\title{
Article \\ Adaptive Responses of Citrus grandis Leaves to Copper Toxicity Revealed by RNA-Seq and Physiology
}

\author{
Fenglin Wu, Huiyu Huang, Mingyi Peng, Yinhua Lai, Qianqian Ren, Jiang Zhang, Zengrong Huang, Lintong Yang $\mathbb{D}^{\mathbb{}}$, \\ Christopher Rensing (1) and Lisong Chen * (1)
}

College of Resources and Environment, Fujian Agriculture and Forestry University, Fuzhou 350002, China; 1180807019@fafu.edu.cn (F.W.); 1180807011@fafu.edu.cn (H.H.); 1200807018@fafu.edu.cn (M.P.); 1200807009@fafu.edu.cn (Y.L.); 3200831041@fafu.edu.cn (Q.R.); 2190807006@fafu.edu.cn (J.Z.); huangzengrong@fafu.edu.cn (Z.H.); talstoy@fafu.edu.cn (L.Y.); rensing@fafu.edu.cn (C.R.)

* Correspondence: lisongchen@fafu.edu.cn; Tel.: +86-591-8385-4966

check for updates

Citation: Wu, F.; Huang, H.; Peng, M.; Lai, Y.; Ren, Q.; Zhang, J.; Huang, Z.; Yang, L.; Rensing, C.; Chen, L.

Adaptive Responses of Citrus grandis Leaves to Copper Toxicity Revealed by RNA-Seq and Physiology. Int. J. Mol. Sci. 2021, 22, 12023.

https://doi.org/10.3390/ijms 222112023

Academic Editor: Farzana Sabir

Received: 11 October 2021

Accepted: 29 October 2021

Published: 6 November 2021

Publisher's Note: MDPI stays neutral with regard to jurisdictional claims in published maps and institutional affiliations.

Copyright: (c) 2021 by the authors. Licensee MDPI, Basel, Switzerland. This article is an open access article distributed under the terms and conditions of the Creative Commons Attribution (CC BY) license (https:// creativecommons.org/licenses/by/ $4.0 /)$.

\begin{abstract}
Copper $(\mathrm{Cu})$-toxic effects on Citrus grandis growth and $\mathrm{Cu}$ uptake, as well as gene expression and physiological parameters in leaves were investigated. Using RNA-Seq, 715 upregulated and 573 downregulated genes were identified in leaves of $C$. grandis seedlings exposed to Cu-toxicity (LCGSEC). Cu-toxicity altered the expression of 52 genes related to cell wall metabolism, thus impairing cell wall metabolism and lowering leaf growth. Cu-toxicity downregulated the expression of photosynthetic electron transport-related genes, thus reducing $\mathrm{CO}_{2}$ assimilation. Some genes involved in thermal energy dissipation, photorespiration, reactive oxygen species scavenging and cell redox homeostasis and some antioxidants (reduced glutathione, phytochelatins, metallothioneins, L-tryptophan and total phenolics) were upregulated in LCGSEC, but they could not protect LCGSEC from oxidative damage. Several adaptive responses might occur in LCGSEC. LCGSEC displayed both enhanced capacities to maintain homeostasis of $\mathrm{Cu}$ via reducing $\mathrm{Cu}$ uptake by leaves and preventing release of vacuolar $\mathrm{Cu}$ into the cytoplasm, and to improve internal detoxification of $\mathrm{Cu}$ by accumulating $\mathrm{Cu}$ chelators (lignin, reduced glutathione, phytochelatins, metallothioneins, L-tryptophan and total phenolics). The capacities to maintain both energy homeostasis and Ca homeostasis might be upregulated in LCGSEC. Cu-toxicity increased abscisates (auxins) level, thus stimulating stomatal closure and lowering water loss (enhancing water use efficiency and photosynthesis).
\end{abstract}

Keywords: Citrus grandis; copper-toxicity; hormones; leaves; photosynthesis; RNA-Seq

\section{Introduction}

Copper $(\mathrm{Cu})$ is required for the proper growth and development of plants, but it is extremely toxic in excess [1,2]. In order to control fruit and leaf fungal diseases, long-term and heavy application of $\mathrm{Cu}$-based fungicides has caused $\mathrm{Cu}$ accumulation in soil of Citrus orchards. The content of available $\mathrm{Cu}$ in the soil increases with Citrus planting years. In the old Citrus orchards, excessive accumulation of $\mathrm{Cu}$ in soil is a common problem limiting Citrus production, especially in acidic soil, and is on the rise [3-6]. The physiological and molecular mechanisms of plant $\mathrm{Cu}$-toxicity and $\mathrm{Cu}$-tolerance have been investigated in some detail. Most studies, however, have focused on phenomena occurring at the roots, because $\mathrm{Cu}$ is mainly accumulated in roots exposed to $\mathrm{Cu}$ toxicity, and the reduction of root growth has been shown to be usually earlier than that of shoot growth [1,7-9]. Less is known about how leaves deal with Cu-toxicity. Growing evidence has shown that $\mathrm{Cu}$ toxicity also influences biosynthesis of photosynthetic pigments, photosynthetic electron transport chain (PETC), $\mathrm{CO}_{2}$ assimilation $[2,10]$, production and detoxification of reactive oxygen species (ROS) [11,12], phenol metabolism [13], hormone biosynthesis [14], nitrogen $(\mathrm{N})$ and carbohydrate metabolism [2,15], and cell wall formation [16].

In roots exposed to $\mathrm{Cu}$-toxicity, most of the $\mathrm{Cu}$ is bound to the cell wall, thus preventing $\mathrm{Cu}$ from entering more sensitive root targets and sensitive shoots, and enhanc- 
ing Cu-tolerance [17]. Therefore, $\mathrm{Cu}$ deposition in the root cell wall is considered as a primary strategy of plant physiology displaying tolerance and detoxification under Cu-toxicity $[18,19]$. In addition to reducing $\mathrm{Cu}$ transport from roots to leaves, different internal detoxification mechanisms of $\mathrm{Cu}$ have been developed in leaves, including compartmentation of $\mathrm{Cu}$ by import to the vacuole, chelation of $\mathrm{Cu}$ by lignin in the cell wall, and intracellular chelation of $\mathrm{Cu}$ by $\mathrm{Cu}$ chelators [viz., amino acids, reduced glutathione (GSH), phytochelatins (PCs), metallothioneins (MTs), organic acids and phenolics], and induction of $\mathrm{Cu}$-tolerant enzymes $[7,9,18,20,21]$. It is worth mentioning that $\mathrm{Cu}$ binding by the cell wall could impair cell wall metabolism, thus limiting leaf cell growth [22,23]. Phytohormones are key signaling molecules and play an important role in the tolerance to heavy metals (HMs) including $\mathrm{Cu}[24,25]$. Exogenous abscisic acid (ABA) mitigated $\mathrm{Cu}-$ toxicity-induced oxidative damage via lowering the accumulation of ROS in Artemisia annua leaves [26]. Brassinosteroid (BR) could alleviate Cu-toxic effects on Raphanus sativus plants by elevating antioxidant enzyme activities and lowering $\mathrm{H}_{2} \mathrm{O}_{2}$ level [27]. Thus, both the biosynthesis and signaling of some phytohormones might be upregulated in leaves exposed to $\mathrm{Cu}$-toxicity to deal with Cu-toxicity. All these processes should be reflected in gene expression profiles.

RNA-Seq provides a powerful way to elucidate the internal detoxification of $\mathrm{Cu}$ in higher plants by monitoring $\mathrm{Cu}$-toxicity-induced alterations of gene expression profiles. Recently, there have been studies investigating Cu-toxic effects on gene expression profiles in plant roots, including melon [28], Arabidopsis [29], rice [30] and wheat [31]. There has been evidence showing that $\mathrm{Cu}$-toxic effects on gene expression differ between roots and leaves [18,32,33]. Fu et al. [33] used whole-transcriptome RNA-Seq to investigate the molecular responses of Citrus junos roots and leaves to Cu-toxicity. A total of 222 and 5734 mRNAs, five and 164 lncRNAs, 17 and 45 circRNAs, and 130 and 147 miRNAs were differentially expressed in leaves and roots of $C$. junos trees exposed to Cu-toxicity, respectively. By contrast, Cao et al. [32] used RNA-Seq to identify more differentially expressed genes (DEGs) in leaves (1161) than in roots (40) of cucumber seedlings exposed to Cu-toxicity. Wan et al. [18] used qRT-PCR to examine Cu-toxic effects on the expression of genes related to $\mathrm{Cu}$ uptake, translocation, homeostasis and detoxification in apple leaves and roots. Cu-toxicity-induced alterations of these genes differed between roots and leaves. However, limited data are available on $\mathrm{Cu}$-toxicity-responsive genes in leaves. Leng et al. [34] and Chen et al. [35] used RNA-Seq to investigate Cu-toxicity-responsive genes in grape leaves. Many genes correlated to ROS detoxification systems (viz., secondary metabolites, antioxidant enzyme and stress-related proteins) were strongly induced. Sudo et al. [36] used DNA microarray to obtained 305 DEGs in leaves of rice plants exposed to $\mathrm{Cu}$-toxicity. A lot of genes involved in the general and the defensive stress response were upregulated, but genes correlated to chlorophyll (Chl) metabolism and photosynthesis were downregulated. In addition, most studies only examined $\mathrm{Cu}$-toxic effects on gene expression profiles in leaves, and did not combine with physiological analysis.

In China, most Citrus are commercially planted in acidic soil, which is vulnerable to Cu-toxicity. Here, RNA-Seq was used to investigate Cu-toxicity-responsive genes in Citrus grandis leaves. Additionally, we investigated Cu-toxic effects on growth and $\mathrm{Cu}$ concentrations in leaves, stems and roots, as well as leaf pigments, gas exchange, relative water content (RWC), hormones, PCs and MTs. The objectives were (a) to test the hypotheses that Cu-toxicity would impair cell wall metabolism, thereby inhibiting leaf growth and that in addition to reducing $\mathrm{Cu}$ transport from roots to leaves, internal detoxification mechanisms of $\mathrm{Cu}$ (viz., $\mathrm{Cu}$ compartmentation, upregulated biosynthesis and signaling of phytohormones) might be involved in leaf Cu-tolerance, and (b) to understand the mechanism underlying $\mathrm{Cu}$-toxicity-induced reduction of photosynthesis at physiological and transcriptional levels. 


\section{Results}

\subsection{Seedling Growth and $\mathrm{Cu}$ Level in Roots, Stems and Leaves}

'Shatian' pummelo [Citrus grandis) (L.) Osbeck] is one of the main rootstocks of pummelo. Recent work from our laboratory indicated that 'Shatian' pummelo had a higher tolerance to $\mathrm{Cu}$-toxicity and was an ideal material to investigate the adaptive mechanism of Cu-toxicity [2,20]. Herein, $400 \mu \mathrm{M} \mathrm{Cu}$ was chosen as the $\mathrm{Cu}$-toxicity treatment because it led to significant but not too severe alterations of biomass, nutrient uptake, photosynthesis and related parameters in C. grandis seedlings [2]. Additionally, we identified more differentially abundant proteins from leaves of $400 \mu \mathrm{M} \mathrm{Cu}$-treated seedlings than from leaves of 200 or $300 \mathrm{Cu}$-treated seedlings [20]. As shown in Figure 1, root and shoot growth was inhibited greatly in $400 \mu \mathrm{M} \mathrm{Cu}$-treated seedlings. Some fibrous roots became dark brown. Young leaf yellowing was observed in some plants. Compared to $0.5 \mu \mathrm{M} \mathrm{Cu}$ treatment (control), the $\mathrm{Cu}$ concentrations in leaves, stems and roots of $400 \mu \mathrm{M} \mathrm{Cu}$-treated seedlings were increased by $494.7 \%, 408.0 \%$ and $929.5 \%$, respectively. Cu concentrations were far higher in roots than in leaves and shoots of $400 \mu \mathrm{M} \mathrm{Cu}$-treated seedlings. Therefore, most of $\mathrm{Cu}$ was accumulated preferentially in roots of $400 \mu \mathrm{M} \mathrm{Cu}$-treated seedlings.
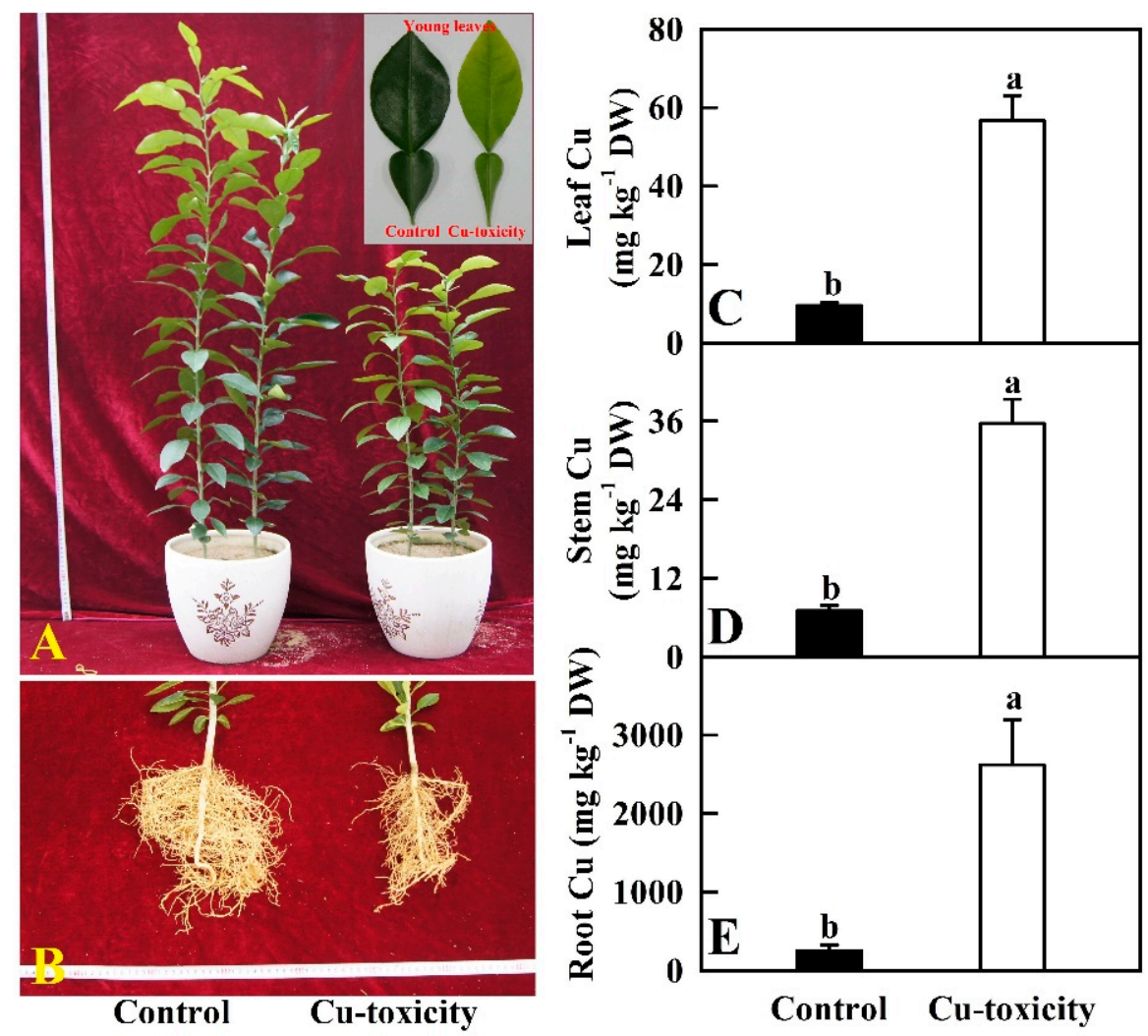

Figure 1. Cu-toxic effects on shoot (A) and root (B) growth, and mean (SE, $n=4)$ concentrations of $\mathrm{Cu}$ in leaves (C), stems (D) and roots (E). Different letters above the bars indicate a significant difference at $p<0.05$.

\subsection{Gas Exchange, Pigments, RWC, PCs and MTs in Leaves}

As shown in Figure 2, Cu-toxicity significantly decreased $\mathrm{CO}_{2}$ assimilation, stomatal conductance $\left(\mathrm{g}_{\mathrm{s}}\right)$, transpiration rate (Tr), water use efficiency (WUE), Chl $a+b$, Car and RWC in leaves by $65.3 \%, 49.9 \%, 38.5 \%, 36.2 \%, 29.5 \%, 19.0 \%$ and $15.4 \%$, respectively, but it significantly increased the ratio of intercellular to ambient $\mathrm{CO}_{2}$ concentration $\left(\mathrm{C}_{\mathrm{i}} / \mathrm{C}_{\mathrm{a}}\right)$, Chl $a / b, \mathrm{Car} / \mathrm{Chl}, \mathrm{PC}$ and MTs concentrations in leaves by $30.1 \%, 11.4 \%, 14.9 \%, 188.8 \%$ and $50.9 \%$, respectively. 

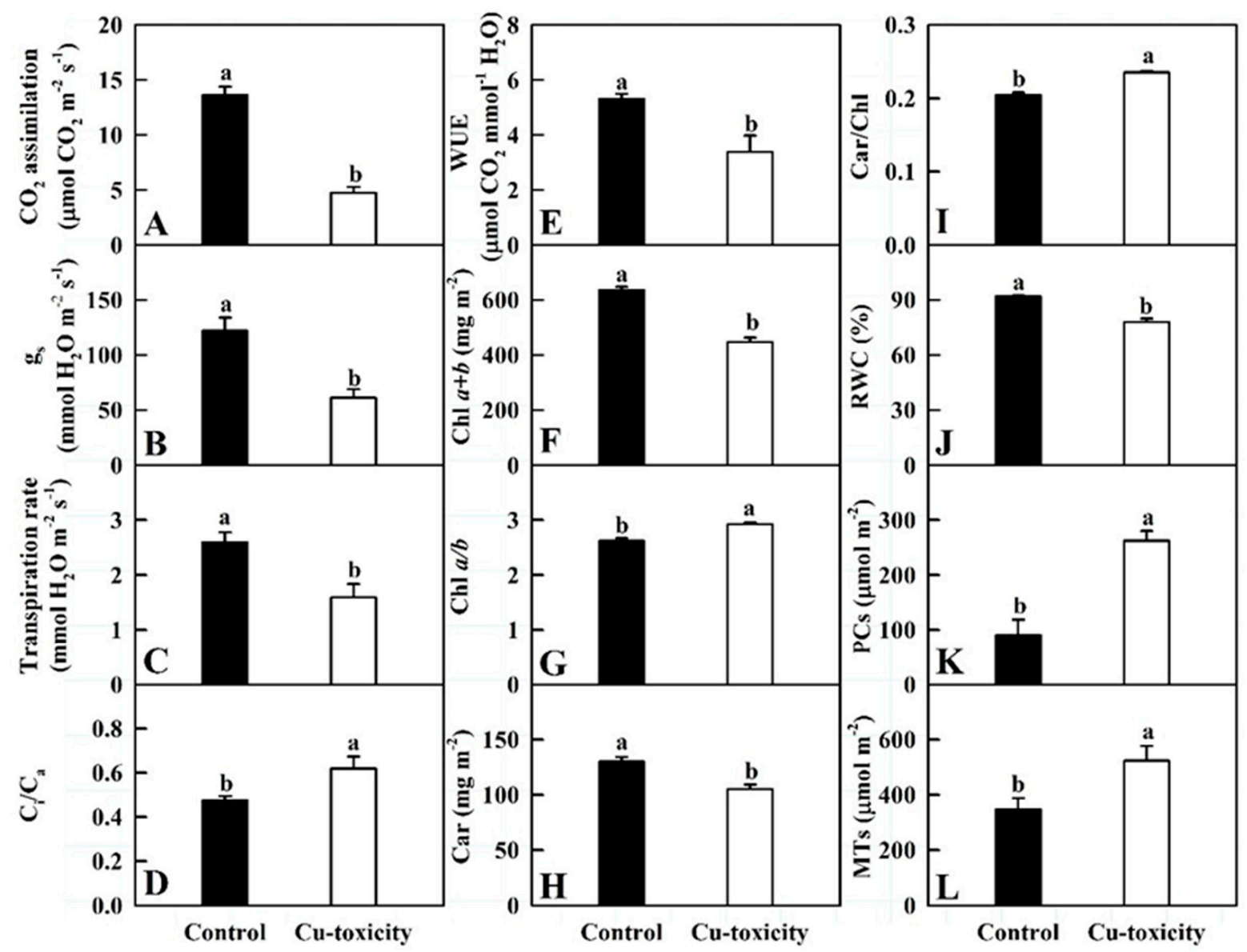

Figure 2. Cu-toxic effects on mean ( $\pm \mathrm{SE}, n=7$ except for 5 for $\mathrm{Chl}$ and Car and 4 for RWC, PCs and MTs) $\mathrm{CO}_{2}$ assimilation (A), stomatal conductance $\left(\mathrm{g}_{\mathrm{s}},(\mathbf{B})\right)$, transpiration rate $(\mathrm{Tr},(\mathrm{C}))$, ratio of intercellular to ambient $\mathrm{CO}_{2}$ concentration $\left(\mathrm{C}_{\mathrm{i}} / \mathrm{C}_{\mathrm{a}},(\mathbf{D})\right)$, water use efficiency (WUE, (E)), chlorophyll (Chl) $a+b(\mathbf{F}), \mathrm{Chl} a / b(\mathbf{G})$, carotenoids (Car, $\left.(\mathbf{H})\right)$, Car $/ \mathrm{Chl}(\mathbf{I})$, relative water content $(\mathrm{RWC},(\mathrm{J}))$, phytochelatins $(\mathrm{PCs},(\mathbf{K}))$ and metallothioneins $(\mathrm{MTs},(\mathbf{L}))$ in leaves. Different letters above the bars indicate a significant difference at $p<0.05$.

\subsection{RNA-Seq and De Novo Assembly}

As shown in Table S1, a total of 47,326,492-5,504,176 raw reads, 46,291,438-53,936,214 clean reads, and 6.94-8.09 G clean bases were generated from six RNA-Seq libraries. Lower error rate $(0.02 \%)$ and reads related to low quality $(0.08-0.13 \%), \mathrm{N}(0.003-0.005 \%)$ and adaptor (1.89-3.32\%), and higher Q20 (97.11-98.12\%), Q30 (91.90-94.42\%) and clean reads (96.6-98.0\%) suggested that the obtained RNA-Seq data were of high quality, which were suitable for further analysis. Herein, $90.61-92.57 \%$ of the clean reads were mapped uniquely to $C$. grandis genome, $44.95 \%$ ( $45.31 \%$ ) of which were mapped to Read 1 (' ' ' chain) and $45.67 \%$ $(45.30 \%)$ of which were mapped to Read 2 ('-' chain), only $2.79 \%-2.95 \%$ of the clean reads were mapped multiply to $C$. grandis genome (Table S2). Similar results have been reported in C. grandis leaves [37], roots [38] and fruits [39]. In this study, a total of 21,775 known genes and 2140 novel genes were annotated in C. grandis leaves (Tables S3 and S4).

\subsection{Functional Annotation and Cu-Toxicity-Responsive Genes}

Here, we identified 573 downregulated and 715 upregulated genes, including 60 upregulated and 45 downregulated transcription factors (TFs; Figure 3A-C and Tables S5 and S6). Cluster analysis showed that the general expression profiles of DEGs were clustered separately in leaves of seedlings treated with 0.5 and $400 \mu \mathrm{M} \mathrm{Cu}$, but were clustered together in three biological replicates per treatment (Figure 3D). 

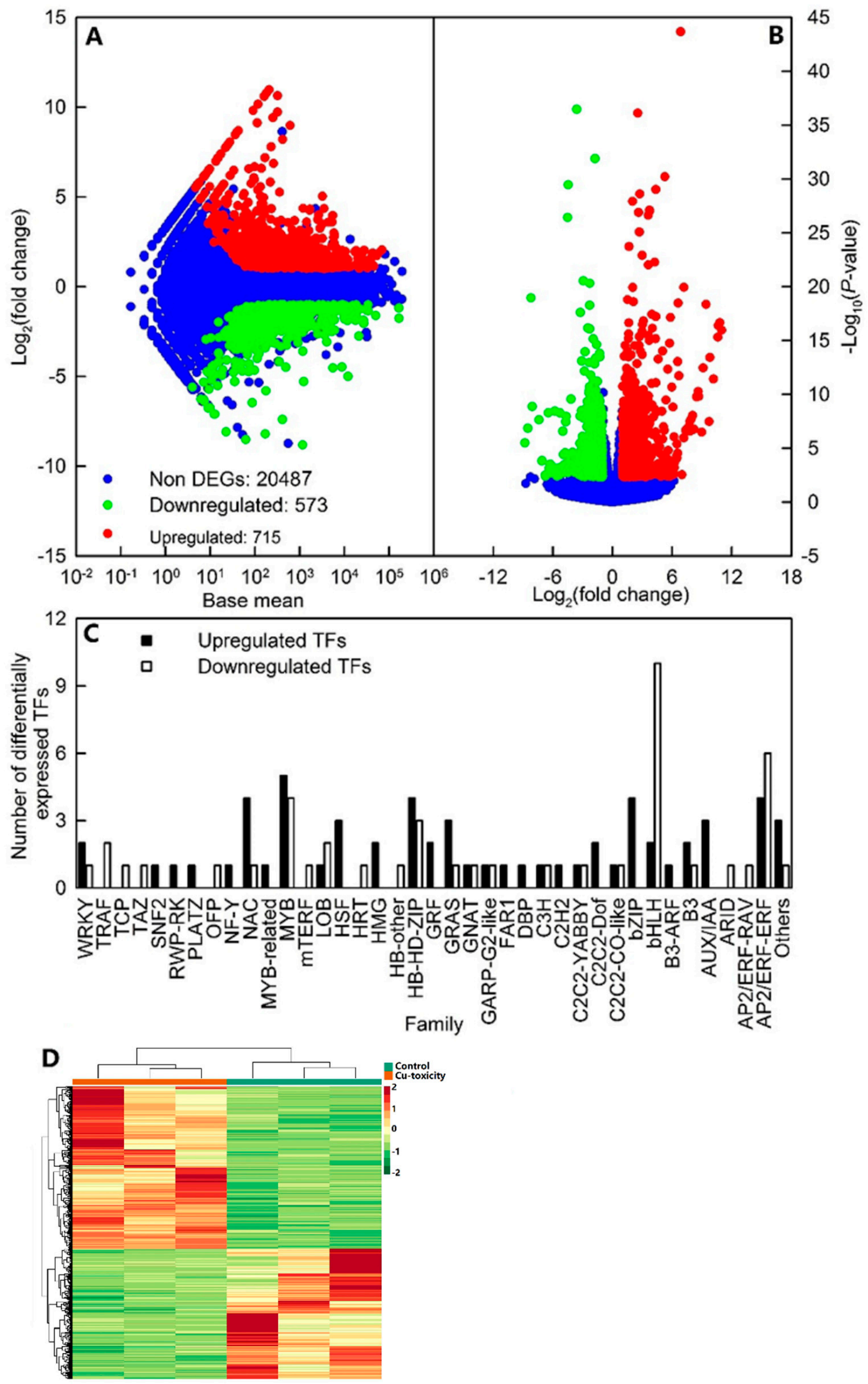

Figure 3. MA map (A) and volcano plot (B) of differentially expressed genes (DEGs), upregulated and downregulated transcription factors (TFs, C), and cluster analysis of DEGs (D) in leaves of C. grandis seedlings exposed to Cu-toxicity (LCGSEC). 
All the assembled high-quality unigenes were first blasted against the National Centre for Biotechnology Information (NCBI) non-redundant protein sequences (NR) database using BLASTX with a cut-off E-value of $10^{-5}$. Majority of these genes displayed a significant sequence identity to Citrus sinensis, Citrus clementina and Citrus unshiu, which contributed $52.21 \%, 24.67 \%$ and $16.45 \%$ of the total assembled genes, respectively (Figure $4 \mathrm{~A}$ ).

All unigenes and DEGs were submitted to euKaryotic Orthologous Groups (KOG) classification for functional prediction (Figure 4B,C). There were 15,219 annotated genes (671 DEGs) assigned to 25 (23) KOG classifications. For all annotated genes, general functional prediction only (3007) contained the most genes, followed by posttranslational modification, protein turnover, chaperones (1553) and signal transduction mechanisms (1399). For DEGs, KOG classification involving the highest number of DEGs was general functional prediction only (97), followed by signal transduction mechanisms (69) and posttranslational modification (68).

All DEGs were subjected to the Kyoto Encyclopedia of Genes and Genomes (KEGG) database for pathway mapping. A total of 510 DEGs were assigned to 129 KEGG pathways. Metabolic pathways (ko01100) were the KEGG pathway having the highest number of DEGs $(258,50.59 \%)$, followed by biosynthesis of secondary metabolites (ko01110, 137, $26.86 \%$ ) and plant-pathogen interaction (ko04626, 57, 11.18\%). Among the 129 KEGG pathways, photosynthesis-antenna proteins (ko00196), fatty acid biosynthesis (ko00061), pyruvate (Pyr) metabolism (ko00620), glycolysis/gluconeogenesis (ko00010), mitogen-activated protein kinases (MAPK) signaling pathway-plant (ko04016), and fatty acid metabolism (ko01212) were significantly enriched at a corrected $p<0.05$ (Figure 4D and Table S7).

A total of 882 DEGs were assigned to 199 Gene Ontology (GO) terms in cellular component, which of three (viz., photosystem (GO:0009521), photosystem I (PSI; GO:0009522), and PSII (GO:0009523) were significantly enriched with an adjusted $p<0.05$. A total of 866 DEGs were mapped to 528 GO terms in molecular function, including 17 significantly enriched GO terms. Tetrapyrrole binding (GO:0046906) was the most significantly enriched GO term in molecular function, followed by pigment binding (GO:0031409) and oxidoreductase activity, acting on paired donors, with incorporation or reduction of molecular oxygen, $\mathrm{NAD}(\mathrm{P}) \mathrm{H}$ as one donor, and incorporation of one atom of oxygen (GO:0016709). A total of 763 DEGs were assigned to 1573 GO terms in biological process, including 30 significantly enriched GO terms. The most significantly enriched GO term in biological process was monocarboxylic acid metabolic process (GO:0032787), followed by monocarboxylic acid biosynthetic process (GO:0072330), and photosynthesis, light harvesting in photosystem I (GO:0009768) (Table S8).

\section{5. qRT-PCR Analysis}

Except for Cg1g015970 and Cg2g038560, Cu-toxicity-induced expression alterations of the other 18 DEGs from RNA-Seq matched well with those from qRT-PCR. There was a significant positive linear correlation between $\mathrm{Cu}$-toxicity-induced alterations of expression levels for the 20 DEGs obtained by qRT-PCR and those obtained by RNA-Seq (Figure S1 and Table S5). Thus, the RNA-Seq results were reliable.

\subsection{Hormones in Leaves}

We detected 34 hormones in leaves, including two ABA and its metabolic products (hereafter referred to as abscisates (ABAs)), namely-ABA and ABA-GE; 10 AUXs, namelyIAA, IAA-Ala, IAA-Phe-Me, IAA-Val, IAN, ICAld, ILA, MEIAA, TRA and TRP; 8 CKs, namely-2MeScZ, BAP7G, cZ9G, DHZR, IPR, oTR, pT and tZR; 1 ETH, namely-ACC; 2 GAs, namely-GA1 and GA24; 7 JAs, namely-H2JA, MEJA, OPC-4, OPC-6, OPDA, JA and JA-ILE; 2 SAs, namely-SA and SAG; and 2 SLs, namely-5DS and ST (Figure 5). Cutoxicity significantly increased the concentrations of ABA, total ABAs, ILA, TRP, total AUXs and cZ9G by $332.7 \%, 703.3 \%, 370.0 \%, 802.7 \%, 776.1 \%$ and $82.5 \%$, respectively, and significantly decreased the concentrations of BAP7G and 5DS by $49.9 \%$ and $25.5 \%$, respectively. Both ABA-GE and IAA were detected only in LCGSEC. The concentrations of 
the other hormones, total CKs, total GAs, total JAs, total SAs and total SLs in leaves were not significantly altered by $\mathrm{Cu}$-toxicity.

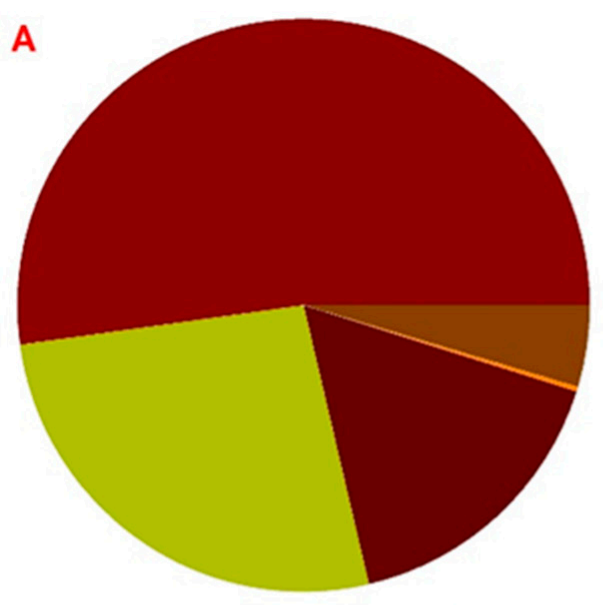

- Citrus sinensis $14514(52.21 \%)$

n Citrus clementina $7359(24.67 \%)$

- Citrus unshiu $4574(16.45 \%)$

n Vitis vinifera $71(0.26 \%)$

n Others $1283(4.61 \%)$
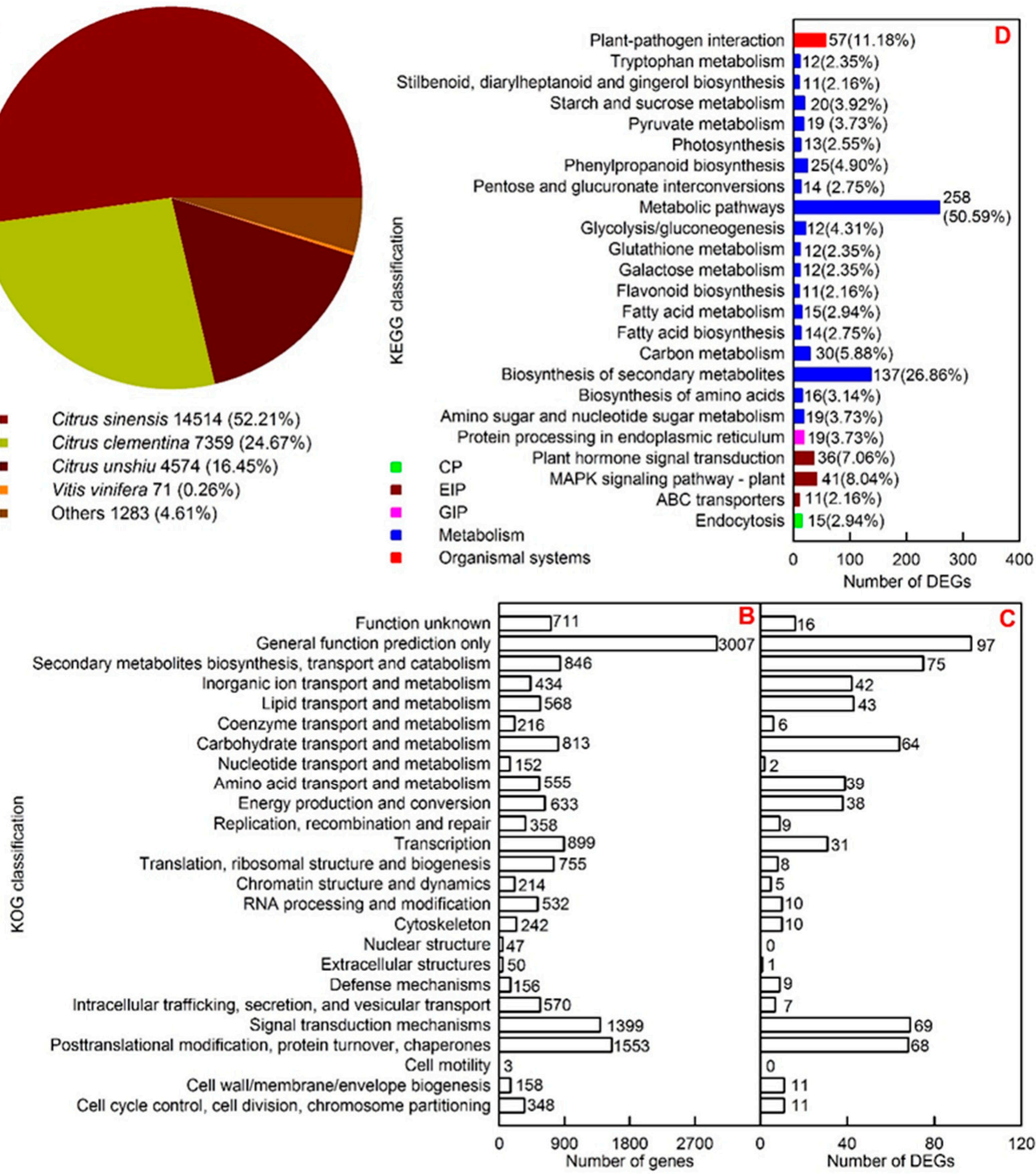

Figure 4. Species distribution of the top Blast hits for C. grandis sequences (A), KOG classification of all annotated genes in C. grandis leaves (B) and DEGs in LCGSEC (C), and KEGG classification of DEGs in LCGSEC (D). 


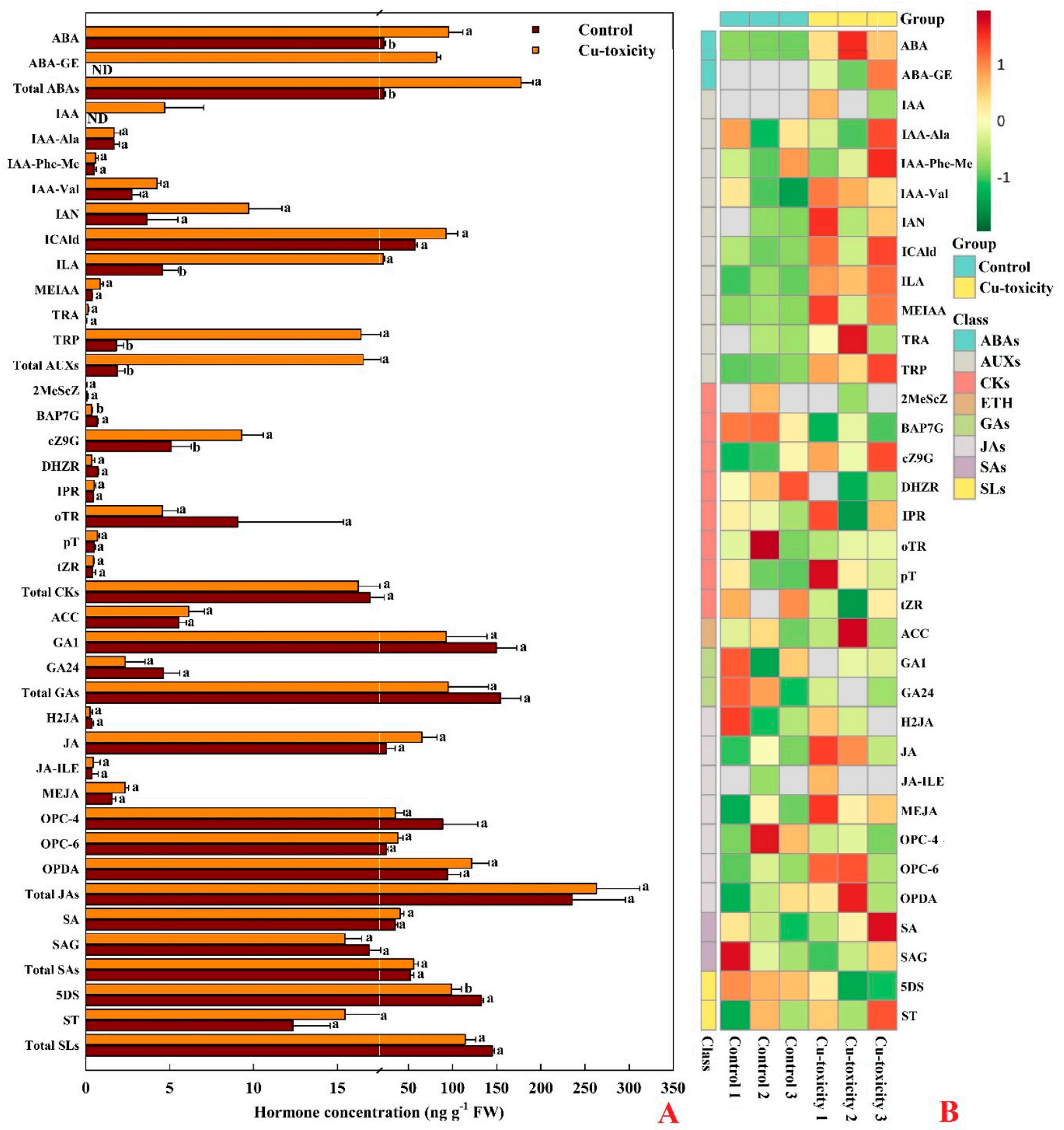

Figure 5. Cu-toxic effects on mean $( \pm \mathrm{SE}, n=3)$ concentrations of hormones in leaves $(\mathrm{A})$ and Heatmap of 34 hormones identified in leaves of $C$. grandis seedlings with 0.5 (control) and 400 (Cu-toxicity) $\mu \mathrm{M} \mathrm{Cu}$ (B). Total ABAs, AUXs, CKs, GAs, JAs, SAs and SLs were the summation of all individual hormone detected for each class. Units for TRP and total AUXs were $\mu \mathrm{g} \mathrm{g}^{-1} \mathrm{FW}$. For the same hormone, different letters above the bars indicate a significant difference at $p<0.05$. ABA-GE, ABA-glucosyl ester; ACC, 1-aminocyclopropanecarboxylic acid; AUXs, auxins; BAP7G, N6-benzyladenine-7-glucoside; CKs, cytokinins; cZ9G, cis-zeatin-9-glucoside; DHZR, dihydrozeatin ribonucleoside; 5DS, 5-deoxystrigol; ETH, ethylene; GA1, gibberellin A1; GA24, gibberellin A24; GAs, gibberellins; H2JA, dihydrojasmonic acid; IAA, indole-3-acetic acid; IAA-Ala, $\mathrm{N}$-(3-indolylacetyl)-L-alanine; IAA-Phe-Me, indole-3-acetyl-L-phenylalanne methyl ester; IAA-Val, N-(3-indolylacetyl)-Lvaline; IAN, 3-indoleacetonitrile; ICAld, indole-3-carboxaldehyde; ILA, indole-3-lactic acid; IPR, N6-isopentenyladenosine; JA, jasmonic acid; JA-ILE, jasmonoyl- L-isoleucine; JAs, jasmonates; MEIAA, methyl indole-3-acetate; MEJA, methyl jasmonate; 2MeScZ, 2-methylthio-cis-zeatin; OPC-4, 3-oxo-2-(2-(Z)-pentenyl) cyclopentane-1-butyric acid; OPC-6, 3-oxo2-(2-(Z)-pentenyl)cyclopentane-1-hexanoic acid; OPDA, cis(+)-12-oxophytodienoic acid, oTR, ortho-topolin riboside; pT, para-topolin; SA, salicylic acid; SAG, salicylic acid 2-O- $\beta$-glucoside; SAs, salicylates; SLs, strigolactones; $S T,( \pm)$ strigol; TRA, tryptamine; TRP, L-tryptophan; tZR, trans-zeatin riboside. 


\section{Discussion}

\subsection{Increased Immobilization of $\mathrm{Cu}$ in Roots, and $\mathrm{Cu}$ Homeostasis and Detoxification in Leaves}

Our results demonstrated that $\mathrm{Cu}$-toxicity increased the accumulation of $\mathrm{Cu}$ in C. grandis roots (Figure 1), thus limiting $\mathrm{Cu}$ to more sensitive shoots and enhancing C. grandis Cu-tolerance [17].

To cope with Cu-toxicity, plants have evolved a conserved and complex network of proteins to maintain $\mathrm{Cu}$ homeostasis, including $\mathrm{Cu}$ transporters, $\mathrm{Cu}$ chaperones and $\mathrm{Cu}$ binding proteins [21,40]. Here, we obtained 12 upregulated and 15 downregulated genes related to $\mathrm{Cu}$ homeostasis in LCGSEC (Table 1). Transporters responsible for the transport of $\mathrm{Cu}$ into the cytoplasm are the high affinity $\mathrm{Cu}$ transporter (COPT) family. COPT1 is involved in $\mathrm{Cu}$ acquisition and transport into leaves [41]. In Arabidopsis, tonoplast COPT5 is important for the export of $\mathrm{Cu}$ from the vacuole [42]. Here, we identified one downregulated COPT5 gene, three downregulated and one upregulated COPT1 genes in LCGSEC. It is worth mentioning that a total of six COPT1 genes (Cg8g023340, Cg8g023350, Cg8g023360, Cg8g023370, Cg8g023380 and Cg6g005770) were identified in C. grandis leaves (Table S3). Wan et al. [18] reported that $\mathrm{Cu}$-toxicity-induced downregulation of COPT5 was greater in higher Cu-tolerant HF/Mp than in less Cu-tolerant HF/Mb ['Hanfu' (Malus domestica) scions grafted on M. prunifolia (Mp) and $M$. baccata $(\mathrm{Mb})$, respectively] leaves, and that the expression level of COPT1 was lower in leaves of HF/Mp than in leaves of HF/Mb when exposed to Cu-toxicity. This might be an adaptive strategy to $\mathrm{Cu}$-toxicity by reducing leaf $\mathrm{Cu}$ concentration and preventing the release of vacuolar $\mathrm{Cu}$ into the cytoplasm. This agrees with the increased accumulation of $\mathrm{Cu}$ in LCGSEC (Figure 1). $\mathrm{Cu}$ is transported by the $\mathrm{COPT} / \mathrm{Ctr}$-like proteins in its reduced form $\mathrm{Cu}(\mathrm{I})$, but most of the bioavailable $\mathrm{Cu}$ form in soil is $\mathrm{Cu}$ (II). The reduction of $\mathrm{Cu}$ (II) to $\mathrm{Cu}$ (I) may facilitate the uptake of $\mathrm{Cu}$ in roots [40]. Ferric reduction oxidase 2 (FRO2) plays a role in Fe uptake and homeostasis [43]. Additionally, $\mathrm{FRO} 2$ can act as a Cu-chelate reductase and facilitate the uptake of $\mathrm{Cu}[40,44]$. FRO7 is involved in Fe uptake by plastids (chloroplasts) [45]. Here, we obtained one upregulated FRO2 (Cg5g041700) gene, and four upregulated FRO7 genes (Cg1g023140, Cg2g021360, Cg5g010410 and Cg6g025130) and one downregulated (Cg8g013730) FRO7 genes in LCGSEC. The Cu-toxicity-induced upregulation of FRO2 and FRO7 might be an adaptive strategy by increasing leaf and chloroplast Fe uptake, because excess $\mathrm{Cu}$ reduced Fe concentration in C. grandis leaves [2]. In addition to the COPT family, zinc (Zn)-regulated transporter (ZRT)- and iron-regulated transporter (IRT)-like proteins (ZIPs) may play a role in $\mathrm{Cu}$ uptake [40]. Here, we obtained two downregulated ZIP genes (Zn transporter 4, chloroplastic and $Z n$ transporter 1) in LCGSEC. Wan et al. [18] observed that Cu-toxicity downregulated the expression of ZIP2 and ZIP4 in leaves, with a greater degree in HF/Mp than in HF/Mb leaves. The transport of the nicotianamine-metal complexes across plant cell membranes is carried out by the members of the Yellow Stripe-Like (YSL) family [21]. Besides maintaining Fe homeostasis, YSL transporters are involved in distribution and redistribution of $\mathrm{Cu}[40]$. Wan et al. [18] found that YSL3 was upregulated and downregulated in HF/Mb and HF/Mp leaves, respectively. Cu-toxicity-induced downregulation of YSL3 and YSL5 in C. grandis leaves might reduce the transport of $\mathrm{Cu}$ - nicotianamine from older to younger leaves, thus protecting younger leaves against $\mathrm{Cu}$-toxicity [46].

$\mathrm{Cu}$ chaperones can assist $\mathrm{Cu}$ intracellular homeostasis by their $\mathrm{Cu}$-chelating ability [47]. Here, we identified one upregulated $C u$ chaperone for superoxide dismutase (CCS, Cg5g009340) in LCGSEC. del Pozo et al. [48] reported similar results in roots and shoots of Arabidopsis seedlings exposed to Cu-toxicity. Wan et al. [18] reported that Cu-toxicity induced the expression of CCS in HF/Mp leaves, but not in HF/Mb leaves. Herein, we obtained three upregulated genes involved $\mathrm{Cu}$ ion binding (Cg2g001710, Cg5g007370 and Cg5g009340) and three upregulated Cu protein genes (Cg8g018870, Cg2g018560 and Cg3g024840) in LCGSEC, implying that these genes played a role in C. grandis Cu-tolerance by binding (cytoplasmic) free $\mathrm{Cu}$ ions [40]. However, Cu-toxicity induced the expression of plastocyanin (Cg3g024680) and two cytochrome c oxidase (Cg9g013180 and CgUng010240) genes in C. grandis leaves. This agrees with the report that excess $\mathrm{Cu}$ reduced the mRNA transcript levels of plastocyanin in Arabidopsis leaves [49]. 
Table 1. DEGs related to $\mathrm{Cu}$ homeostasis in LCGSEC.

\begin{tabular}{|c|c|c|c|}
\hline $\begin{array}{l}\text { Accession } \\
\text { No. }\end{array}$ & KEGG & Swiss-Prot & $\log _{2}(\mathrm{FC})$ \\
\hline \multicolumn{4}{|c|}{$\mathrm{Cu}$ ion transmembrane transporter activity (GO:0005375) } \\
\hline Cg4g018610 & Solute carrier family 31 (copper transporter), member 1 & Copper transporter 5; AtCOPT5 & -1.317 \\
\hline Cg8g023350 & Solute carrier family 31 (copper transporter), member 1 & Copper transporter 1; AtCOPT1 & -3.606 \\
\hline Cg8g023360 & Solute carrier family 31 (copper transporter), member 1 & Copper transporter 1; AtCOPT1 & -1.076 \\
\hline Cg8g023380 & Solute carrier family 31 (copper transporter), member 1 & Copper transporter 1; AtCOPT1 & -8.212 \\
\hline Cg6g005770 & Solute carrier family 31 (copper transporter), member 1 & Copper transporter 1 ; AtCOPT1 & 3.407 \\
\hline \multicolumn{4}{|c|}{ Yellow Stripe-Like (YSL) family } \\
\hline Cg5g018670 & Fanconi-associated nuclease 1 [EC:3.1.21.- 3.1.4.1] & $\begin{array}{l}\text { Metal-nicotianamine transporter YSL3; Protein } \\
\text { YELLOW STRIPE LIKE 3; AtYSL3 }\end{array}$ & -1.609 \\
\hline Cg5g020560 & Fanconi-associated nuclease 1 [EC:3.1.21.- 3.1.4.1] & $\begin{array}{l}\text { Probable metal-nicotianamine transporter YSL5; } \\
\text { Protein YELLOW STRIPE LIKE 5; AtYSL5 }\end{array}$ & -1.066 \\
\hline \multicolumn{4}{|c|}{ Cu ion binding (GO:0005507) and/or Cu proteins } \\
\hline Cg1g028930 & L-ascorbate oxidase [EC:1.10.3.3] & L-ascorbate oxidase & -3.067 \\
\hline Cg2g001710 & $\begin{array}{l}\text { Enoyl-[acyl-carrier protein] reductase I } \\
\text { [EC:1.3.1.9 1.3.1.10] }\end{array}$ & $\begin{array}{c}\text { Enoyl-[acyl-carrier-protein] reductase [NADH], } \\
\text { chloroplastic }\end{array}$ & 1.679 \\
\hline Cg2g018560 & Iron transport multicopper oxidase & L-ascorbate oxidase homolog & 1.069 \\
\hline Cg3g024840 & Iron transport multicopper oxidase & L-ascorbate oxidase homolog & 1.455 \\
\hline Cg3g024680 & Plastocyanin & Plastocyanin, chloroplastic & -1.448 \\
\hline Cg5g007370 & Glutamate dehydrogenase $\left(\mathrm{NAD}(\mathrm{P})^{+}\right)[\mathrm{EC}: 1.4 .1 .3]$ & Glutamate dehydrogenase 2 & 1.745 \\
\hline Cg5g009340 & Copper chaperone for superoxide dismutase & $\begin{array}{l}\text { Copper chaperone for superoxide dismutase, } \\
\text { chloroplastic/cytosolic; AtCCS }\end{array}$ & 1.588 \\
\hline Cg7g012360 & Glutathione S-transferase [EC:2.5.1.18] & Glutathione S-transferase F9 & -1.318 \\
\hline Cg8g018870 & Superoxide dismutase, $\mathrm{Cu}-\mathrm{Zn}$ family [EC:1.15.1.1] & Superoxide dismutase [Cu-Zn], chloroplastic & 1.344 \\
\hline Cg9g013180 & Cytochrome c oxidase subunit 3 & Cytochrome c oxidase subunit 3 & -1.324 \\
\hline CgUng010240 & Cytochrome c oxidase subunit 2 & Uncharacterized mitochondrial protein AtMg00530 & -1.581 \\
\hline \multicolumn{4}{|c|}{ Cu chaperones } \\
\hline Cg5g009340 & Copper chaperone for superoxide dismutase & $\begin{array}{l}\text { Copper chaperone for superoxide dismutase, } \\
\text { chloroplastic/cytosolic; AtCCS }\end{array}$ & 1.588 \\
\hline \multicolumn{4}{|c|}{ Others } \\
\hline Cg3g000750 & $\mathrm{Cd}^{2+} / \mathrm{Zn}^{2+}$-exporting ATPase [EC:3.6.3.3 3.6.3.5] & Cadmium/zinc-transporting ATPase HMA2 & -1.403 \\
\hline Cg4g006740 & $\begin{array}{l}\text { Solute carrier family } 39 \text { (zinc transporter), } \\
\text { member } 1 / 2 / 3\end{array}$ & Zinc transporter 4, chloroplastic; ZRT/IRT-like protein 4 & -1.718 \\
\hline Cg8g022750 & $\begin{array}{l}\text { Solute carrier family } 39 \text { (zinc transporter), } \\
\text { member } 1 / 2 / 3\end{array}$ & Zinc transporter 1; ZRT/IRT-like protein 1; OsZIP1 & -2.937 \\
\hline Cg5g041700 & Ferric-chelate reductase [EC:1.16.1.7] & $\begin{array}{c}\text { Ferric reduction oxidase 2; AtFRO2; EC = 1.16.1.7; } \\
\text { Ferric-chelate reductase } 2\end{array}$ & 3.591 \\
\hline Cg1g023140 & $\begin{array}{l}\text { Ferric-chelate reductase [EC:1.16.1.7] I (RefSeq) ferric } \\
\text { reduction oxidase 7, chloroplastic-like (A) }\end{array}$ & NAC domain-containing protein 104 \{ECO:0000305\} & 3.271 \\
\hline $\mathrm{Cg} 2 \mathrm{~g} 021360$ & $\begin{array}{l}\text { Ferric-chelate reductase [EC:1.16.1.7] I (RefSeq) ferric } \\
\text { reduction oxidase 7, chloroplastic-like (A) }\end{array}$ & NAC domain-containing protein 72 & 2.012 \\
\hline Cg5g010410 & $\begin{array}{l}\text { Ferric-chelate reductase [EC:1.16.1.7] I (RefSeq) ferric } \\
\text { reduction oxidase 7, chloroplastic-like (A) }\end{array}$ & $\begin{array}{l}\text { NAC domain-containing protein } 100 \\
\text { \{ECO:0000303 | PubMed:15029955\} }\end{array}$ & 1.441 \\
\hline Cg6g025130 & $\begin{array}{l}\text { Ferric-chelate reductase [EC:1.16.1.7] I (RefSeq) ferric } \\
\text { reduction oxidase 7, chloroplastic-like (A) }\end{array}$ & $\begin{array}{l}\text { NAC domain-containing protein } 100 \\
\{\text { ECO:0000303 | PubMed:15029955\} }\end{array}$ & 1.777 \\
\hline Cg8g013730 & $\begin{array}{l}\text { Ferric-chelate reductase [EC:1.16.1.7] I (RefSeq) ferric } \\
\text { reduction oxidase 7, chloroplastic-like (A) }\end{array}$ & NAC domain-containing protein 90 & -1.805 \\
\hline
\end{tabular}

FC: fold change.

$\mathrm{Cu}$ chelators play a role in internal accumulation mechanisms, in which the complexation of $\mathrm{Cu}$ can increase $\mathrm{Cu}$ immobilization in organelles such as vacuole or cell wall. The present findings and our recent work demonstrated that $\mathrm{Cu}$-toxicity increased the accumulation of PCs, MTs (Figure 2), TRP (Figure 5), GSH, total phenolics and lignin [50] in C. grandis leaves, implying that internal accumulation mechanisms played a role in $\mathrm{Cu}$-tolerance of $C$. grandis leaves.

\subsection{Cu-Toxic Effects on Cell Wall Metabolism in Leaves}

As shown in Table S9, 32 downregulated and 20 upregulated genes related to cell wall metabolism were identified in LCGSEC. Wall-associated receptor kinases (WAKs) play a role in cell expansion and in defense against abiotic stress in plants. Hou et al. [51] 
demonstrated that WAKL4 expression was induced by excess $\mathrm{Cu}$ in Arabidopsis, and that an Arabidopsis WAKL4 T-DNA insertional mutant was hypersensitive to excess $\mathrm{Cu}$. Xia et al. [16] observed that RNAi-mediated WAK11 knockdown lowered rice Cu-tolerance through enhancing $\mathrm{Cu}$ level in cytoplasm of roots and shoots and lowering $\mathrm{Cu}$ concentration in the cell wall (pectin and hemicellulose) of roots and shoots due to increased degree of pectin methylesterification, possibly because of decreased activity of pectin methylesterase in roots and shoots. Here, we identified five downregulated and one upregulated pectinesterase genes involved in pectin de-esterification, one downregulated omega-hydroxypalmitate O-feruloyl transferase involved in the cell wall pectin biosynthetic process, and two downregulated and two upregulated WAKs in LCGSEC, implying that pectin biosynthesis and the degree of pectin methylesterification were downregulated and upregulated in these leaves, respectively, thus decreasing and increasing $\mathrm{Cu}$ concentration in the cell wall and cytoplasm, respectively, and hence lowering Cu-tolerance. Xyloglucan is a major hemicellulose component in the cell wall of dicotyledonous plants [52]. Xyloglucan endotransglucosylase/hydrolases (XTHs) were shown to catalyze either the hydrolysis of xyloglucan through xyloglucan endohydrolase (XEH) activity and/or the endotransglycosylation of xyloglucan through xyloglucan endotransglucosylase (XET) activity, thus loosening the cell wall. Zhu et al. $[53,54]$ observed that $x$ th31 and $x$ th17 Arabidopsis mutants had decreased xyloglucan content, slower root elongation, and less aluminum (Al) level in the root tips and cell wall, but higher Al-tolerance than wild-type plants. Here, we obtained two downregulated $\mathrm{XTHs}$, indicating that $\mathrm{Cu}$-toxicity might reduce xyloglucan level in LCGSEC, thus decreasing $\mathrm{Cu}$ accumulation. This agrees with a report showing that the $\mathrm{Cu}$ level was reduced in the cell wall hemicellulose and pectin in WAK11-RNAi transgenic rice roots and leaves [16]. To conclude, excess $\mathrm{Cu}$ might impair leaf cell wall metabolism, thus inhibiting leaf growth and lowering $\mathrm{Cu}$-tolerance.

\subsection{Cu-Toxic Effects on Pigment Metabolism, Photosynthesis, and Carbon, Carbohydrate and Energy Metabolisms in Leaves}

$\mathrm{Cu}$-toxicity-induced decreases in $\mathrm{g}_{\mathrm{s}}$ and $\operatorname{Tr}$ (Figure 2) agrees with our transcriptome data that Cu-toxicity inhibited the expression of E3 ubiquitin-protein ligase RZFP34 involved in stomatal opening, but induced the expression of heat shock $70 \mathrm{kDa}$ protein $1 / 2 / 6 / 8$ involved in stomatal closure. However, $\mathrm{Cu}$-toxicity-induced reduction of $\mathrm{CO}_{2}$ assimilation was not only explained by reduced $g_{s}$, because $C_{i} / C_{a}$ ratio displayed an increasing trend in LCGSEC (Figure 2). The reduction in Chl level (Figure 2) might be due to reduced biosynthesis, as indicated by reduced expression of genes involved in $\mathrm{Chl}$ biosynthesis, and increased catabolization, as indicated by increased expression of genes involved in Chl catabolism, while the reduction in Car level (Figure 2) might be due to decreased biosynthesis, as indicated by decreased expression of geranylgeranyl pyrophosphate synthase involved in Car biosynthesis. Cu-toxicity-induced inhibition of photosynthesis could not be explained by reduced photosynthetic pigment levels alone, because $\mathrm{Cu}$-toxicity affected $\mathrm{CO}_{2}$ assimilation much more than photosynthetic pigments (Figure 2). Here, we isolated 35 downregulated and 12 upregulated genes involved in photosynthesis (ko00195; 12 downregulated and one upregulated genes), photosynthesis-antenna proteins (ko00196; eight downregulated genes), PSI (GO:0009522; 12 downregulated and one upregulated genes), PSII (GO:0009523; 14 downregulated and one upregulated genes), PETC (GO:0009767; three downregulated and one upregulated genes), PSII oxygen evolving complex (OEC, GO:0009654; four downregulated genes), photosynthesis, light reaction (GO:0019684; 12 downregulated and one upregulated genes) and thylakoid (GO:0009579; 29 downregulated and nine upregulated genes). By contrast, we only identified six upregulated genes involved in photosynthesis, dark reaction (GO:0019685) and carbon fixation in photosynthetic organisms (ko00710) (Table S10). Thus, it is reasonable to assume that $\mathrm{Cu}$-toxicity-induced reduction in leaf $\mathrm{CO}_{2}$ assimilation was mainly caused by an impaired light reaction, including $(a)$ whole PETC (viz., photosynthesis-antenna proteins, light reaction, PSI, PSII, and PSII OEC) and (b) thylakoid $[2,9,34]$, rather than by an impaired dark reaction. This is also supported by 
the report that quite a few of the genes related to PETC were downregulated in leaves of rice plants exposed to Cu-toxicity [36].

We obtained 43 upregulated and 16 downregulated genes involved in carbon, carbohydrate and energy metabolisms, including carbon metabolism (ko01200; 24 upregulated and six downregulated genes), starch and sucrose metabolism (ko00500; 15 upregulated and five downregulated genes), glycolysis/gluconeogenesis (ko00010; 16 upregulated and six downregulated genes), glycolytic process (GO:0006096; eight upregulated genes); Pyr metabolism (ko00620; 17 upregulated and two downregulated genes), citrate cycle [tricarboxylic acid (TCA) cycle] (ko00020; eight upregulated genes), ATP biosynthetic process (GO:0006754; eight upregulated and two downregulated genes), and ATP generation from ADP (GO:0006757; eight upregulated genes) in LCGSEC (Table S11). Thus, these physiological processes might be upregulated in these leaves. Cu-toxicity-induced upregulation of carbon metabolism and starch and sucrose metabolism agrees with increased accumulation of glucose, fructose, sucrose and starch in LCGSEC [2]. The increased accumulation of starch might be due to increased biosynthesis, as indicated by the upregulated expression of two genes encoding 1,4-alpha-glucan branching enzyme and one gene encoding isoamylase involved in starch biosynthesis, and reduced catabolization, as indicated by downregulated expression of two genes ( $\alpha$-amylase and $\beta$-amylase) correlated to starch catabolic process. The higher level of sucrose might be mainly due to elevated biosynthesis, as indicated by enhanced expression of two genes encoding sucrose synthase and one gene encoding sucrose-phosphate synthase, rather than by reduced catabolization, as indicated by elevated expression of one gene encoding $\beta$-fructofuranosidase. The elevated levels of glucose and fructose might be associated with increased formation, as indicated by enhanced expression of one $\beta$-fructofuranosidase gene involved in sucrose degradation, and two $\beta$-glucosidase and two glucan endo-1,3- $\beta$-glucosidase $1 / 2 / 3$ genes involved in glucose formation.

Stressed plants often suffer from an energy deficit. Stress tolerance is highly correlated to energy availability in plants. The upregulation of glycolysis in roots of rice and roots and leaves of Citrus seedlings exposed to $\mathrm{Al}$ has been suggested to be an adaptive mechanism through maintaining basic respiration and meeting an elevated requirement for energy $[37,38,55,56]$. Mitochondria, the site of respiration and ATP synthesis, have a key role in energy metabolism. Thus, the Cu-toxicity-induced upregulation of genes involved in glycolysis/gluconeogenesis, glycolysis, Pyr metabolism, TCA cycle, ATP biosynthetic process and ATP generation from ADP might be an adaptive strategy for maintaining energy homeostasis and preventing energy shortage.

\subsection{Cu-Toxic Effects on Thermal Dissipation, ROS Scavenging and Cell Redox Homeostasis in Leaves}

More excess excitation energy might exist in LCGSEC due to reduced $\mathrm{CO}_{2}$ assimilation (Figure 2). If not rapidly dissipated, the excess excitation energy can potentially stimulate the generation of ROS. Excess excitation energy can be safely removed by xanthophyll cycle-dependent thermal dissipation before it reaches PSII reaction centers (RCs). Photorespiration can also dissipate excess light energy by consuming NADPH and ATP [57]. $\mathrm{Cu}$-toxicity-induced upregulation of violaxanthin de-epoxidase involved in xanthophyll cycle and three genes involved in photorespiration (Cg4g009780, Cg6g010200 and Cg4g021720) agrees with the elevated demand for excess light energy dissipation. However, Cu-toxicity inhibited the expression of catalase (CAT) involved in scavenging $\mathrm{H}_{2} \mathrm{O}_{2}$ produced by photorespiration (Table S12). Because Cu-toxicity stimulated the generation of ROS in C. grandis leaves [2], both the expression of some genes correlated to ROS scavenging and the levels of some antioxidants should be altered in LCGSEC. Superoxide dismutase (SOD) can rapidly dismutase superoxide anion into $\mathrm{H}_{2} \mathrm{O}_{2}$ and $\mathrm{O}_{2}$. Our findings that $\mathrm{Fe} / \mathrm{Mn}$-SOD and $\mathrm{Cu} / \mathrm{Zn}$-SOD (CSD) were downregulated and upregulated in LCGSEC, respectively is in agreement with the reports that Fe-SOD abundance was reduced and CSD abundance was elevated in Cu-sufficient Arabidopsis leaves [58] and that Cu-toxicity increased CSD abundance, but had no influence on Fe-SOD abundance in C. grandis leaves [20]. Plants that suppress $F e-S O D$ and induce $C S D$ under $\mathrm{Cu}$-toxicity can keep superoxide anion scavenging 
and prevent the $\mathrm{Cu}$-toxic effect on photosynthesis by buffering $\mathrm{Cu}$ concentration $[11,58,59]$. Similarly, Cu-toxicity induced the expression of CCS in leaves (Table S12), as reported in Arabidopsis [59]. CCS has been shown to bind $\mathrm{Cu}$ ions and deliver them specifically to CSD, thereby activating CSD [60]. Additionally, both CCS and CSD have been suggested to play a role in $\mathrm{Cu}$ homeostasis [18,44]. Ascorbate (ASC) peroxidase (APX) catalyzes the reduction of $\mathrm{H}_{2} \mathrm{O}_{2}$ into $\mathrm{H}_{2} \mathrm{O}$ using ASC as the reducing agent. Davletova et al. [61] reported that cytosolic APX1 played a key role in protecting the chloroplast against photooxidative damage. Here, Cu-toxicity induced the expression of cytosolic APX2 (Cg6g002810) in leaves (Table S12). Besides protecting plant cells from oxidative damage by quenching reactive molecules by the addition of GSH, glutathione S-transferases (GSTs) play a role in the detoxification of HMs including $\mathrm{Cu}$ [62]. Lim et al. [62] found that transgenic Dianthus superbus plants overexpressing a tobacco Tau class GST (Nt107) had higher biomass, $\mathrm{CO}_{2}$ assimilation and $\mathrm{Cu}$ accumulation than wild type plants when exposed to excess $\mathrm{Cu}$, concluding that transgenic plants enhanced PCs biosynthesis, thereby sequestering and detoxifying excess $\mathrm{Cu}$. Here, we identified one upregulated and seven downregulated GSTs in LCGSEC (Table S12). This agrees with our report that LCGSEC had increased accumulation of GSH [50]. However, Leng et al. [34] identified 27 upregulated and three downregulated GSTs in grape leaves exposed to Cu-toxicity. Peroxidases (PODs) can reduce $\mathrm{H}_{2} \mathrm{O}_{2}$ to $\mathrm{H}_{2} \mathrm{O}$ using a wide variety of substrates as electron donor. Here, we obtained two upregulated and five downregulated PODs in LCGSEC. However, only seven upregulated PODs were observed in grape leaves exposed to Cu-toxicity [34]. Additionally, we obtained three downregulated and five upregulated genes related to cell redox homeostasis (GO:0045454) in LCGSEC. In conclusion, some genes correlated to thermal dissipation, photorespiration, ROS scavenging and cell redox homeostasis (Table S12) and the levels of some antioxidants such as PCs, MTs, TRP (Figures 2 and 5), GSH and total phenolics [50] were upregulated in LCGSEC, but they could not sufficiently protect these leaves from oxidative damage, because MDA level [50] and electrolyte leakage [2] were increased in LCGSEC.

\subsection{Cu-Toxic Effects on Calcium Signaling and MAPK Signaling in Leaves}

Calcium (Ca) signaling and MAPK signaling are the major signaling networks involved in the toxicity of $\mathrm{HMs}$ including $\mathrm{Cu}$ [24]. We obtained 29 downregulated and 11 upregulated genes involved in Ca homeostasis, including Ca ion transmembrane transporter activity (GO:0015085; five downregulated and four upregulated genes), Ca-mediated signaling (GO:0019722; one upregulated and one downregulated genes), CaM binding (GO:0005516; 12 downregulated and five upregulated genes), CaM-dependent protein kinase activity (GO:0004683; one upregulated gene), Ca ion binding (GO:0005509; 14 downregulated and three upregulated genes), and Ca channel activity (GO:0005262; two upregulated genes) in LCGSEC (Table S13). In plants, various $\mathrm{Ca}^{2+}$-binding proteins can act as $\mathrm{Ca}^{2+}$-sensors to monitor the alterations of cytosolic $\mathrm{Ca}^{2+}$ concentration $\left(\left[\mathrm{Ca}^{2+}\right]_{\mathrm{cyt}}\right)$, including calmodulins (CaMs), calcineurin B-like proteins (CBLs), CaM like proteins (CMLs), and $\mathrm{Ca}^{2+}$-dependent protein kinases (CDPKs) [24]. CaMs work through binding to and regulating the activities of diverse downstream target proteins called "CaM-binding proteins" (CaMBPs), which provide another level of specificity for Ca signaling [63]. $\mathrm{Ca}^{2+}$ transport molecules, $\mathrm{Ca}^{2+}$ buffers and $\mathrm{Ca}^{2+}$ sensors are involved in the maintenance of $\mathrm{Ca}^{2+}$ homeostasis [64]. Here, we identified three downregulated [Ca-transporting ATPase 9, plasma membrane-type (ACA9, Cg5g012700) and ACA12 (Cg2g020060 and Cg5g034830)] and one upregulated [ACA12 (Cg3g010620)] AUTOINHIBITED $\mathrm{Ca}^{2+}$-ATPase (ACA) genes involved in the translocation of $\mathrm{Ca}^{2+}$ from the cytosol out of the cell or into the organelle, one upregulated Ca-transporting ATPase 4, endoplasmic reticulum (ER)-type (ECA4, Cg6g003500) involved in the translocation of $\mathrm{Ca}^{2+}$ from the cytosol into an endomembrane compartment, two downregulated vacuolar cation/proton exchanger 3 (CAX3) genes (Cg6g006900 and $\mathrm{Cg} 8 \mathrm{~g} 024060)$ involved in the translocation of $\mathrm{Ca}^{2+}$ into the vacuole; one upregulated $\mathrm{Ca}$ uniporter protein 2, mitochondrial ( $\mathrm{Cg} 3 \mathrm{~g} 022310)$ involved in the uptake of mitochondrial $\mathrm{Ca}$, and one upregulated glutamate receptor 2.8 (GLR2.8, Cg4g022490), a non-selective cation 
channel involved in the regulation of $\mathrm{Ca}^{2+}$ influx into cell in LCGSEC (Table S13), indicating that $\mathrm{Ca}^{2+}$ influx into the cytosol and $\mathrm{Ca}^{2+}$ influx into endomembrane compartment (ER and mitochondrium) might be enhanced, but $\mathrm{Ca}^{2+}$ efflux out of cytosol into the cell exterior and sequestration into vacuole might be downregulated in these leaves, thereby maintaining $\mathrm{Ca}^{2+}$ homeostasis in the cytosol and the endomembrane compartment, because excess $\mathrm{Cu}$ reduced Ca level in C. grandis leaves [2] and that Cg3g010620 (ACA12) might be involved in the translocation of $\mathrm{Ca}^{2+}$ from the cytosol into the organelle. Here, we obtained 14 downregulated and three upregulated genes involved in $\mathrm{Ca}^{2+}$ binding in LCGSEC, indicating that the amount of $\mathrm{Ca}^{2+}$ bound to $\mathrm{Ca}^{2+}$ buffering proteins might be reduced in these leaves, thus contributing to $\mathrm{Ca}^{2+}$ homeostasis in the cytosol. Additionally, most of DEGs [12 downregulated (Cg2g020060, Cg3g013020, Cg3g012090, Cg8g018400, Cg2g014880, Cg8g018410, Cg5g018340, Cg8g018470, Cg5g006140, Cg5g034830, Cg4g002250 and Cg5g012700) and five upregulated (Cg9g029620, $\mathrm{Cg} 9 \mathrm{~g} 027140, \mathrm{Cg} 2 \mathrm{~g} 043490, \mathrm{Cg} 3 g 010620$ and $\mathrm{Cg} 8 \mathrm{~g} 010170)$ genes] involved in CaM binding were downregulated in LCGSEC.

We obtained one upregulated GLR2.8 (Cg4g022490) and one downregulated protein RALF-like 32 (RALFL32; Cg9g014450) related to Ca-mediated signaling, and one upregulated [Ca/CaM-dependent protein kinase (CaM kinase) II (CCaMKII, Cg8g010170)] and six downregulated [four CMLs (Cg1g003570, Cg2g011280, Cg3g017200 and Cg6g011100), CaM (Cg3g021480) and CBL (Cg5g018200)] genes encoding Ca sensors in LCGSEC (Table S13). A deletion of AtGLR3.5 caused premature senescence and a decrease in Chl level in Arabidopsis leaves [65]. A deletion of AtGLR3.4 led to decreased photosynthetic yield of PSII and non-photochemical quenching [66]. ZmCCaMK is considered to play a key role in ABA- and BR-induced antioxidant protection in maize leaves $[67,68]$. Rapid alkalinization factor (RALF) led to rapid alkalization of the cell wall by mediating a transient elevation of $\left[\mathrm{Ca}^{2+}\right]_{\text {cyt }}$, thus inhibiting cell growth in tissue culture [69]. Transgenic Arabidopsis plants overexpressing RALF22 or RALF23 displayed decreased growth and less tolerance to salt stress [70]. Thus, Cu-toxicity-induced upregulation of GLR2.8 and CCaMKII and downregulation of RALFL32 might contribute to $C$. grandis $\mathrm{Cu}$-tolerance. Except for CCaMKII, all the other six Ca sensor genes were downregulated in LCGSEC, probably contributing to $\mathrm{Ca}^{2+}$ homeostasis, because all the six $\mathrm{Ca}$ sensors were $\mathrm{Ca}^{2+}$ binding proteins.

We identified 29 downregulated and 12 upregulated genes involved in the MAPK signaling pathway-plant (ko04016) in LCGSEC (Table S14). MAPK-signaling cascade includes three protein kinases [MAPKs, MAPK kinases (MAPKKs) and MAPKK kinases (MAPKKKs)] acting in a sequential manner to activate different downstream targets. MAPKs can be stimulated by specific metal ligands or indirectly by ROS produced due to metal stress [24]. Yeh et al. [71] reported that $\mathrm{Cu}^{2+}$ induced MAPK activation by distinct ROS generating systems in rice roots. Additionally, ABA induced a rapid and transient MAPK activation in pea leaves [72]. Thus, Cu-toxicity might increase ABA accumulation (Figure 5) and ROS generation [2], thus inducing MAPKK4/5 (MKK4/5) expression in C. grandis leaves. This agrees with a report that two novel rice MAPK genes (OsMSRMK3 and OsWJUMK1) in rice leaves were induced by $\mathrm{Cu}$-toxicity, $\mathrm{ABA}$ and $\mathrm{H}_{2} \mathrm{O}_{2}$ [73]. These results demonstrated the involvement of MAPKs in mediating Cu-toxicity. Protein phosphatases $2 \mathrm{C}$ (PP2Cs) are the negative regulators of stress-induced receptor kinase signaling, MAPK pathways and ABA signaling [74]. Here, we identified five upregulated genes encoding protein phosphatase $2 \mathrm{C}$ (PP2C) in LCGSEC (Table S14). Overexpression of an ABA, salt and drought inducible rice PP2C gene, OsPP108 conferred Arabidopsis tolerance to drought, mannitol, salt stress and ABA insensitivity [75]. Liu et al. [76] indicated that $A$. thaliana protein phosphatase $2 C$ G Group 1 positively regulated salt stress in an ABA-dependent manner. Therefore, the upregulation of PP2Cs might be an adaptive response to Cu-toxicity. To conclude, our findings demonstrated the involvement of the MAPK signaling pathway in $\mathrm{Cu}$-tolerance and toxicity.

\subsection{Cu-Toxic Effects on Biosynthesis and Signaling of Phytohormones in Leaves}

As shown in Tables S15-S17, we identified 24 upregulated and 12 downregulated genes involved in plant hormone signal transduction (ko04075), 37 upregulated and 28 downreg- 
ulated genes involved in auxin (AUX)-, GA-, ETH-, BR-, ABA-, SA-, CK- and JA-mediated or activated signaling pathways, 22 upregulated and 15 downregulated genes involved in ABA, CK, AUX, BR, SA, JA and GA metabolism in LCGSEC. Cu-toxicity increased the concentrations of ABA, ILA, TRP, and CZ9G, decreased the concentrations of BAP7G and 5DS, but did not affect the concentrations of the other 28 hormones in leaves (Figure 5). These results indicated the involvement of hormone signaling in Cu-tolerance of $C$. grandis leaves.

Ouzounidou and Ilias [77] demonstrated that IAA alleviated Cu-toxic effects on sunflower seedlings by improving photosynthesis and WUE. Leng et al. [34] reported that all $A U X$ response factors ( $A R F s$ ) were inhibited and most genes encoding IAA synthase and AUX/IAA proteins were induced in grape leaves exposed to Cu-toxicity, suggesting that the IAA regulated genes might positively regulate grape development and $\mathrm{Cu}$-tolerance. Here, we obtained four upregulated and two downregulated genes correlated to AUX signal transduction, 11 upregulated and eight downregulated genes correlated to AUX-activated signaling pathway, four upregulated and one downregulated genes correlated to AUX biosynthetic process, and seven upregulated and three downregulated genes correlated to AUX transport in LCGSEC. Additionally, Cu-toxicity increased the levels of IAA, TRP and total AUXs in leaves (Figure 5). These results suggested that AUX biosynthesis, levels and signal signaling might be upregulated in LCGSEC, which might enhance Cu-tolerance of C. grandis leaves via promoting $\mathrm{CO}_{2}$ assimilation and WUE.

We detected six upregulated [five $P P 2 C$ s and one $A B A$ responsive element binding factor (ABF)] and two downregulated (two $A B A$ receptor PYL4) and 11 upregulated and 8 downregulated genes involved in ABA signal transduction and ABA-mediated signaling pathway, respectively in LCGSEC, implying that ABA signaling might be upregulated in these leaves. However, one upregulated and four downregulated genes correlated to the ABA biosynthetic process were identified in LCGSEC. The downregulation of ABA biosynthesis-related genes caused by $\mathrm{Cu}$-toxicity might be due to feedback inhibition caused by large increase of ABA level in these leaves [78]. This agrees with the reports that both the level of ABA and the expression of genes [CsPP2C5, CsABI1, Cucumis sativus SNF1related kinase 2.3 (CsSnRK2.3), CsSnRK2.4 and most CsPYLs] involved in ABA signaling were upregulated in cucumber seeds exposed to Cu-toxicity [79], and that the level of ABA was increased in leaves of sunflower seedlings exposed to Cu-toxicity [80]. ABA is well-known for its ability to stimulate stomatal closure. Cu-toxicity-induced increase in ABA level might stimulate stomatal closure, thus reducing transpiration water loss, because $g_{s}$, Tr and RWC were reduced in LCGSEC (Figure 2). ABA has been suggested to have a positive and synergistic relationship with the biosynthesis of GSH and PCs [81]. Cu-toxicity-induced increase of ABA concentration might improve the biosynthesis of GSH and PCs, as indicated by increased accumulation of GSH [50] and PCs (Figure 5) in LCGSEC. Zehra et al. [26] reported that ABA alleviated Cu-toxicity-induced oxidative damage in $A$. annua leaves by reducing ROS production. The increased accumulation of $\mathrm{ABA}$ is also in agreement with the increased requirement for ROS scavenging [2].

One upregulated histidine-containing phosphotransfer peotein 4 (AHP4) and one downregulated two-component response regulator $A R R$ - $B$ family $(A R R-B)$ involved in CK signal transduction, two upregulated genes (Cg1g013900 and Cg5g001740) involved in CK-activated signaling pathway, and one upregulated CK riboside $5^{\prime}$-monophosphate phosphoribohydrolase LOG7 involved in the conversion from inactive CK nucleotides to the biologically active freebase forms [82] were identified in LCGSEC (Table S17). Additionally, Cu-toxicity increased cZ9G levels, and decreased BAP7G levels, but did not significantly alter the levels of total CKs and other CKs in leaves (Figure 5). Thus, both the levels of the active free-base form CKs and CK signaling might be upregulated in these leaves. Thomas et al. [83] reported that isopentenyltransferase (IPT)-induced CKs in transgenic tobacco enhanced Cu-tolerance and decreased $\mathrm{Cu}$-toxicity-induced lipid peroxidation in leaves, which was explained by an upregulated expression of a MT-like gene (MT-L2) in leaves. Cu-toxicity might increase the levels of active CKs, thus enhancing the level of MTs and Cu-tolerance of $C$. grandis leaves. 


\section{Materials and Methods}

\subsection{Plant Culture and $\mathrm{Cu}$ Treatments}

Plant culture and $\mathrm{Cu}$ treatments were carried out as described by Li et al. [2] and Huang et al. [50]. Briefly, 13-week-old 'Shatian' pummelo (Citrus grandis (L.) Osbeck) seedlings grown in $6 \mathrm{~L}$ pots (two plants pot ${ }^{-1}$ ) containing sand in a greenhouse with natural photoperiod at Fujian Agriculture and Forestry University, Fuzhou $\left(26^{\circ} 5^{\prime} \mathrm{N}, 119^{\circ} 14^{\prime}\right.$ E) with annual average sunshine hours, temperature and relative humidity of $\sim 1600 \mathrm{~h}, 20^{\circ} \mathrm{C}$ and $76 \%$, respectively [84], were irrigated 6 times weekly for 6 months with freshly prepared nutrition solution at a $\mathrm{Cu}$ level of 0.5 or $400 \mu \mathrm{M}$ from $\mathrm{CuCl}_{2}$ until there was nutrient solution leaking out of the small hole at the bottom of the pot $(\sim 500 \mathrm{~mL})$. The $\mathrm{pH}$ of the nutrient solutions was adjusted to 4.8 with $\mathrm{HCl}$ to prevent $\mathrm{Cu}$ precipitation. Twenty pots (a total of 40 plants) in each treatment were arranged at random. Thereafter, the most recent, fully expanded mature leaves at $\sim 7$ weeks of age were selected for all analyses. After leaf gas exchange measurements, leaves without petioles, winged leaves and midribs and leaf discs of 6-mm-diameter were harvested from the same plants used for gas exchange measurements at sunny noon, frozen in liquid $\mathrm{N}_{2}$, and then stored at $-80^{\circ} \mathrm{C}$ until RNA and metabolite extraction. The unsampled seedlings were selected for the measurements of $\mathrm{Cu}$ in leaves, stems and roots, and RWC in leaves.

\subsection{Cu Concentration in Leaves, Stems and Roots}

The fully expanded mature leaves without petioles, midribs and winged leaves, the middle sections of stems and the fibrous roots were taken for subsequent analysis [85]. Leaf, stem and root $\mathrm{Cu}$ concentration was determined with a NexION 300X Inductively Coupled Plasma Mass Spectrometer (ICP-MS, PerkinElmer, Shelton, CT, USA) after $0.2 \mathrm{~g}$ of samples were digested in 5:1 (v:v) of $\mathrm{HNO}_{3}: \mathrm{HClO}_{4}$ [2].

\subsection{Gas Exchange, Pigments, RWC, PCs and MTs in Leaves}

Leaf gas exchange measurements were performed with a CIRAS-2 portable photosynthesis system (PP systems, Herts, UK) at an ambient $\mathrm{CO}_{2}$ concentration $\left(\sim 410 \mu \mathrm{mol} \mathrm{mol}^{-1}\right)$ and a controlled light intensity of $\sim 1000 \mu \mathrm{mol} \mathrm{m}^{-2} \mathrm{~s}^{-1}$ between 9:30 and 10:30 a.m. on a sunny day [2].

Leaf Chl $a, \mathrm{Chl} b$ and carotenoids (Car) concentrations were measured after being extracted with $80 \%$ (v:v) acetone [86].

Leaf RWC were assayed using weighing method [87].

Leaf GSH and total non-protein thiols (TNP-SH) were extracted and assayed according to Garg and Kaur [88]. Four leaf discs $\left(0.2826 \mathrm{~cm}^{2}\right.$ in size $)$ were extracted with $2 \mathrm{~mL}$ of ice-cold $5 \%(\mathrm{w}: \mathrm{v})$ sulphosalicylic acid. For the GSH assay, $0.5 \mathrm{~mL}$ of supernatant was mixed with $0.6 \mathrm{~mL}$ of $100 \mathrm{mM}(\mathrm{pH} 7.0)$ phosphate buffer and $40 \mu \mathrm{L}$ of $1 \mathrm{mM}$ 5,5-dithiobis-2nitrobenzoic acid (DTNB). After $2 \mathrm{~min}$, the absorbance was read at $412 \mathrm{~nm}$. For the TNP-SH assay, $100 \mu \mathrm{L}$ of supernatant was mixed with $0.5 \mathrm{~mL}$ of $0.1 \mathrm{M}$ phosphate buffer (pH 7.0) containing $0.5 \mathrm{mM}$ EDTA and $0.5 \mathrm{~mL}$ of $1 \mathrm{mM}$ DTNB. After $10 \mathrm{~min}$, the absorbance was read at $412 \mathrm{~nm}$. The difference between TNP-SH and GSH was considered to represent PCs.

Leaf MTs was extracted and measured according to Malik et al. [89]. Four leaf discs $\left(0.2826 \mathrm{~cm}^{2}\right.$ in size) were homogenized in $1.6 \mathrm{~mL}$ of ice-cold solution containing $0.5 \mathrm{M}$ sucrose, $20 \mathrm{mM}$ Tris- $\mathrm{HCl}$ buffer, $\mathrm{pH} 8.6$ and $0.01 \% \beta$-mercaptoethanol. After being centrifuged at $30,000 \times g$ for $20 \mathrm{~min} .1 \mathrm{~mL}$ of supernatant was mixed with $1 \mathrm{~mL}$ of cold ethanol and $80 \mu \mathrm{L}$ of chloroform; the mixtures were then centrifuged at $6000 \times \mathrm{g}$ for $10 \mathrm{~min}$ at $4{ }^{\circ} \mathrm{C}$. The collected supernatant was mixed with $1 \mathrm{mg}$ RNA and $40 \mu \mathrm{L}$ of $37 \% \mathrm{HCl}$ and subsequently with $3 \mathrm{~mL}$ of cold ethanol. The sample was maintained at $-20^{\circ} \mathrm{C}$ for $1 \mathrm{~h}$, then centrifuged at $6000 \times g$ for $10 \mathrm{~min}$. The MTs containing pellet was washed with $87 \%$ ethanol and was re-suspended in $150 \mu \mathrm{L}$ of $0.25 \mathrm{M} \mathrm{NaCl}$ and $150 \mu \mathrm{L}$ of $1 \mathrm{M} \mathrm{HCl}$ containing $4 \mathrm{mM}$ EDTA. A volume of $4.2 \mathrm{~mL}$ $\mathrm{NaCl}(2 \mathrm{M})$ containing $0.43 \mathrm{mM}$ DTNB buffered with $0.2 \mathrm{M} \mathrm{Na}$-phosphate $(\mathrm{pH} 8)$ was added to the sample at room temperature. The sample was finally centrifuged at $3000 \times g$ for $5 \mathrm{~min}$, and the supernatant was measured as absorbance at $412 \mathrm{~nm}$. 


\subsection{Leaf RNA Extraction and RNA-Seq}

Total RNA was extracted from $200 \mathrm{mg}$ of frozen leaves mixed equally from four plants (one plant pot ${ }^{-1}$ ) using Recalcitrant Plant Total RNA Extraction Kit (Bioteke Corporation, Beijing, China). There were three biological replicates per treatment. A total of six sequencing libraries were constructed according to Guo et al. [37,38] and sequenced on Illumina HiSeq platform (Illumina Inc., San Diego, CA, USA) at Wuhan MetWare Biotechnology Co., Ltd. (www.metware.cn, accessed on 1 March 2021). The raw transcriptome data have been deposited in NCBI SRA database (accession number: PRJNA702620).

\subsection{RNA-Seq Analysis}

The raw sequencing reads were filtered using fastp v0.7.0 [90]. High-quality clean reads obtained after filtering were mapped to the genome of pummelo downloaded from the genome website (http:// citrus.hzau.edu.cn/orange/download/index.php, accessed on 1 January 2021) directly using HISAT2. The mapped reads of each sample were assembled using StringTie v1.3.4b [91]. The expression level of each gene was given as fragment per kilobase of transcript per million mapped reads (FPKM). Differential expression analysis between two samples was carried out by DESeq2 software using the counts from featureCounts [92]. Then, we used Benjamini and Hochberg's method to adjust the $p$-valve and obtain the false discovery rate (FDR). Screening criteria for DEGs were $\mid \log _{2}$ (fold change) $\mid \geq 1$ and FDR $<0.05$. Gene functions were annotated according to Swiss-Prot, TrEMBL, KEGG, NR, GO, KOG and Protein family (Pfam) [93].

\section{6. $q R T-P C R$ Validation}

Twenty DEGs were randomly selected for qRT-PCR validation. Total RNA was extracted from leaves according to the method described above. There were 3 replicates per treatment. The sequences of the Forward and Reverse primers designed using Primier version 5.0 (Premier Biosoft International, CA, USA) were listed in Table S18. qRT-PCR was run in 2 technical replicates. U4/U6 small nuclear ribonucleoprotein PRP31 (PRPF31; Cg7g019550) and actin (Cg1g026080) were selected as internal standards [37].

\subsection{Extraction and Measurements of Hormones in Leaves}

Approximately $50 \mathrm{mg}$ frozen leaves were ground into powder in liquid $\mathrm{N}_{2}$, and extracted with $1 \mathrm{~mL}$ of methanol:water:formic acid (15:4:1, v:v:v). After centrifugation, the extracts were collected, evaporated to dryness in $\mathrm{N}_{2}$ flow, reconstituted in $100 \mu \mathrm{L}$ of $80 \%$ methanol $(v / v)$, and filtered through a $0.22 \mu \mathrm{m}$ filter for further liquid chromatographmass spectrometer (LC-MS) analysis. Hormones were assayed by MetWare (http:/ / www. metware.cn/, accessed on 1 March 2021) based on the AB Sciex QTRAP 6500 liquid chromatography-tandem mass spectrometry (LC-MS/MS) platform [94].

\subsection{Statistical Analysis}

Results represented the mean \pm SE $(n=3-5)$. Comparison between two treatment means was carried out in SigmaPlot 10 (Systat Software, Inc., San Jose, CA, USA, http: / / systasoftware.com, accessed on 1 May 2021) using a one-tailed $t$-test at $p<0.05$. For Hierarchical Cluster Analysis (HCA), the data were normalized and analyzed by R software (https:/ / www.r-project.org/, accessed on 1 May 2021).

\section{Conclusions}

Thirty-two upregulated and 20 downregulated genes related to cell wall metabolism were identified in LCGSEC, implying that Cu-toxicity might impair cell wall metabolism, thus reducing leaf growth and lowering $\mathrm{Cu}$-tolerance. $\mathrm{Cu}$-toxicity decreased and increased the expression of genes involved in $\mathrm{Chl}$ biosynthesis and degradation, respectively, thus reducing $\mathrm{Chl}$ concentration, while $\mathrm{Cu}$-toxicity-induced reduction in Car concentration might be mainly due to decreased biosynthesis. The reduction in leaf $\mathrm{CO}_{2}$ assimilation caused by $\mathrm{Cu}$-toxicity might be due to impaired PETC, as indicated by the downregulated expression 
of related genes. Although some genes related to thermal dissipation, photorespiration, ROS scavenging and cell redox homeostasis and some antioxidants were upregulated in LCGSEC, but antioxidant systems as a whole could not protect LCGSEC from oxidative damage. In addition to reducing $\mathrm{Cu}$ transport from roots to shoots, several adaptive responses might occur in LCGSEC. A model for the adaptive responses of $C$. grandis leaves to $\mathrm{Cu}$-toxicity was proposed through the integration of the present findings and available data in the previous literatures (Figure 6). LCGSEC displayed enhanced capacities to maintain homeostasis of $\mathrm{Cu}$ via reducing $\mathrm{Cu}$ uptake by leaves and preventing vacuolar $\mathrm{Cu}$ into the cytoplasm, as indicated by altered expression of genes encoding $\mathrm{Cu}$ transporters, $\mathrm{Cu}$ chaperones and $\mathrm{Cu}$-binding proteins and to improve internal detoxification of $\mathrm{Cu}$, as indicated by increased accumulation of selected Cu chelators. LCGSEC displayed increased capacities to maintain both energy homeostasis by upregulating the expression of genes involved in energy (ATP) production and Ca homeostasis by altering the expression of related genes. Cu-toxicity increased the concentrations of ABAs (AUXs), thus stimulating stomatal closure and reducing water loss (improving WUE and photosynthesis).

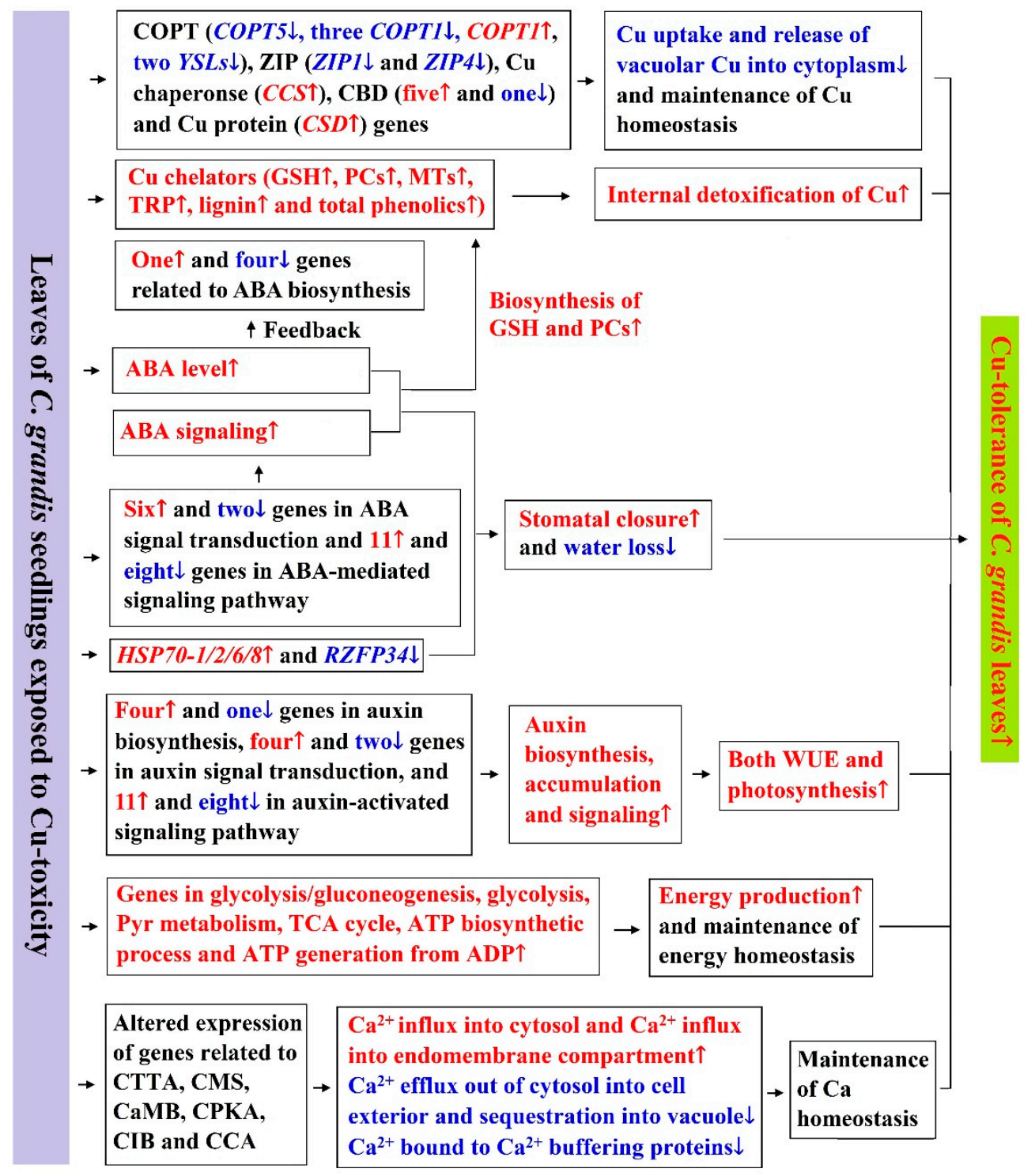

Figure 6. A potential model for the adaptive responses of $C$. grandis leaves to Cu-toxicity. CaMB, CaM binding; CCA, Ca channel activity; CIB, Ca ion binding; CMS, Ca-mediated signaling; CPKA, CaM-dependent protein kinase activity; CTTA, Ca ion transmembrane transporter activity; HSP70-1/2/6/8, heat shock 70kDa protein 1/2/6/8; Red, upregulation; $\uparrow$,upregulation; Blue, downregulation; $\downarrow$, downregulation. 
Supplementary Materials: The following are available online at https://www.mdpi.com/article/10 $.3390 /$ ijms222112023/s1.

Author Contributions: Conceptualization, F.W., Z.H., L.Y. and L.C.; Data Curation, F.W., H.H. and L.C.; Formal Analysis, F.W.; Funding Acquisition, L.C.; Investigation, F.W., H.H., M.P., Y.L., Q.R. and J.Z.; Methodology, F.W., H.H. and L.C.; Project Administration, L.C.; Resources, L.C.; Supervision, Z.H., L.Y. and L.C.; Writing-Original Draft, F.W.; Writing-Review and Editing, C.R. and L.C. All authors have read and agreed to the published version of the manuscript.

Funding: This research was funded by the National Key Research and Development Program of China (2018YFD1000305), the National Natural Science Foundation of China (32072511) and the Special Found for Scientific and Technological Innovation of Fujian Agriculture and Forestry University (CXZX2020071A).

Institutional Review Board Statement: Not applicable.

Informed Consent Statement: Not applicable.

Data Availability Statement: The raw transcriptome data have been deposited in NCBI SRA database (accession number: PRJNA702620). Data are archived in L.-S. Chen's lab and available upon request.

Conflicts of Interest: The authors declare no conflict of interest. The funders had no role in the design of the study; in the collection, analyses, or interpretation of data; in the writing of the manuscript, or in the decision to publish the results.

\section{References}

1. Adrees, M.; Ali, S.; Rizwan, M.; Ibrahim, M.; Abbas, F.; Farid, M.; Ziaurrehman, M.; Irshad, M.K.; Bharwana, S.A. The effect of excess copper on growth and physiology of important food crops: A review. Environ. Sci. Pollut. Res. 2015, 22, 8148-8162. [CrossRef]

2. Li, Q.; Chen, H.-H.; Qi, Y.-P.; Ye, X.; Yang, L.-T.; Huang, Z.-R.; Chen, L.-S. Excess copper effects on growth, uptake of water and nutrients, carbohydrates, and PSII photochemistry revealed by OJIP transients in Citrus seedlings. Environ. Sci. Pollut. Res. 2019, 26, 30188-30205. [CrossRef] [PubMed]

3. Cheng, C.; Zhang, S.-Q.; Lin, W.-J.; Chen, H.-H.; Lin, F.; Zhu, D.-H.; Chen, L.-S.; Li, Y.; Guo, J.-X. Soil copper (Cu) nutrient status and its influencing factors in pomelo orchards in Pinghe county, Fujian Province. J. Fruit Sci. 2018, 35, 301-310.

4. Li, Y.; Han, M.-Q.; Lin, F.; Ten, Y.; Lin, J.; Zhu, D.-H.; Guo, P.; Weng, Y.-B.; Chen, L.-S. Soil chemical properties, 'Guanximiyou' pummelo leaf mineral nutrient status and fruit quality in the southern region of Fujian province, China. J. Soil Sci. Plant Nutr. 2015, 15, 615-628. [CrossRef]

5. Huang, Y.Y.; Liu, B.; Chen, G.F.; Wang, Y. Content of copper in soil, Citrus leaves, and branch roots of Citrus orchards in Guangxi. Southwest China J. Agric. Sci. 2007, 20, 1060-1063.

6. Alva, A.K.; Huang, B.; Prakash, O.; Paramasivam, S. Effects of copper rates and soil pH on growth and nutrient uptake by Citrus seedlings. J. Plant Nutr. 1999, 22, 1687-1699. [CrossRef]

7. Kumar, V.; Pandita, S.; Sidhu, G.P.S.; Sharma, A.; Khanna, K.; Kaur, P.; Bali, A.S.; Setia, R. Copper bioavailability, uptake, toxicity and tolerance in plants: A comprehensive review. Chemosphere 2021, 262, 127810. [CrossRef]

8. Wan, H.; Du, J.; He, J.; Lyu, D.; Li, H. Copper accumulation, subcellular partitioning and physiological and molecular responses in relation to different copper tolerance in apple rootstocks. Tree Physiol. 2019, 39, 1215-1234. [CrossRef]

9. Shabbir, Z.; Sardar, A.; Shabbir, A.; Abbas, G.; Shamshad, S.; Khalid, S.; Natasha; Murtaza, G.; Dumat, C.; Shahid, M. Copper uptake, essentiality, toxicity, detoxification and risk assessment in soil-plant environment. Chemosphere 2020, $259,127436$. [CrossRef]

10. Cai, L.-Y.; Zhang, J.; Ren, Q.-Q.; Lai, Y.-H.; Peng, M.-Y.; Deng, C.-L.; Ye, X.; Yang, L.-T.; Yang, Z.-R.; Chen, L.-S. Increased $\mathrm{pH}$-mediated alleviation of copper-toxicity and growth response function in Citrus sinensis seedlings. Sci. Hortic. 2021, 288, 110310. [CrossRef]

11. Zhang, H.; Zhang, F.; Xia, Y.; Wang, G.; Shen, Z. Excess copper induces production of hydrogen peroxide in the leaf of Elsholtzia haichowensis through apoplastic and symplastic CuZn-superoxide dismutase. J. Hazard. Mater. 2018, 178, 834-843. [CrossRef] [PubMed]

12. Hippler, F.W.R.; Boaretto, R.M.; Dovis, V.L.; Quaggio, J.A.; Azevedo, R.A.; Mattos, D., Jr. Oxidative stress induced by Cu nutritional disorders in Citrus depends on nitrogen and calcium availability. Sci. Rep. 2018, 8, 1641. [CrossRef]

13. Kováčik, J.; Klejdus, B.; Hedbavny, J.; Štork, F.; Bačkor, M. Comparison of cadmium and copper effect on phenolic metabolism, mineral nutrients and stress-related parameters in Matricaria chamomilla plants. Plant Soil 2009, 320, 231-242. [CrossRef]

14. Lequeux, H.; Hermans, C.; Lutts, S.; Verbruggen, N. Response to copper excess in Arabidopsis thaliana: Impact on the root system architecture, hormone distribution, lignin accumulation and mineral profile. Plant Physiol. Biochem. 2010, 48, 673-682. [CrossRef] [PubMed] 
15. Zhang, L.L.; He, X.J.; Chen, M.; An, R.D.; An, X.L.; Li, J. Responses of nitrogen metabolism to copper stress in Luffa cylindrica roots. J. Soil Sci. Plant Nutr. 2014, 14, 616-624. [CrossRef]

16. Xia, Y.; Yin, S.; Zhang, K.; Shi, X.; Shen, Z. Oswak11, a rice wall-associated kinase, regulates Cu detoxification by alteration the immobilization of cu in cell walls. Environ. Exp. Bot. 2018, 150, 99-105. [CrossRef]

17. Shi, K.; Liu, X.; Zhu, Y.; Bai, Y.; Shan, D.; Zheng, X.; Wang, L.; Zhang, H.; Wang, C.; Yan, T.; et al. MdWRKY11 improves copper tolerance by directly promoting the expression of the copper transporter gene MdHMA5. Hortic. Res. 2020, 7, 105. [CrossRef]

18. Wan, H.; Yang, F.; Zhuang, X.; Cao, Y.; He, J.; Li, H.; Qin, S.; Lyu, D. Malus rootstocks affect copper accumulation and tolerance in trees by regulating copper mobility, physiological responses, and gene expression patterns. Environ. Pollut. 2021, 287, 117610. [CrossRef]

19. Wang, Q.Y.; Liu, J.S.; Hu, B. Integration of copper subcellular distribution and chemical forms to understand copper toxicity in apple trees. Environ. Exp. Bot. 2016, 123, 125-131. [CrossRef]

20. Huang, W.-L.; Wu, F.-L.; Huang, H.-Y.; Huang, W.-T.; Deng, C.-L.; Yang, L.-T.; Huang, Z.-R.; Chen, L.-S. Excess copper-induced alterations of protein profiles and related physiological parameters in Citrus leaves. Plants 2020, 9, 291. [CrossRef]

21. Printz, B.; Lutts, S.; Hausman, J.F.; Sergeant, K. Copper trafficking in plants and its implication on cell wall dynamics. Front. Plant Sci. 2016, 7, 601. [CrossRef] [PubMed]

22. Bouazizi, H.; Jouili, H.; Geitmann, A.; El Ferjani, E. Cell wall accumulation of Cu ions and modulation of lignifying enzymes in primary leaves of bean seedlings exposed to excess copper. Biol. Trace Elem. Res. 2011, 139, 97-107. [CrossRef]

23. Vinit-Dunand, F.; Epron, D.; Alaoui-Sossé, B.; Badot, P.M. Effects of copper on growth and on photosynthesis of mature and expanding leaves in cucumber plants. Plant Sci. 2002, 163, 53-58. [CrossRef]

24. Jalmi, S.K.; Bhagat, P.K.; Verma, D.; Noryang, S.; Tayyeba, S.; Singh, K.; Sharma, D.; Sinha, A.K. Traversing the links between heavy metal stress and plant signaling. Front. Plant Sci. 2018, 9, 12. [CrossRef]

25. Thao, N.P.; Khan, M.I.; Thu, N.B.; Hoang, X.L.; Asgher, M.; Khan, N.A.; Tran, L.S. Role of ethylene and its cross talk with other signaling molecules in plant responses to heavy metal stress. Plant Physiol. 2015, 169, 73-84. [CrossRef]

26. Zehra, A.; Choudhary, S.; Wani, K.I.; Naeem, M.; Khan, M.M.A.; Aftab, T. Exogenous abscisic acid mediates ROS homeostasis and maintains glandular trichome to enhance artemisinin biosynthesis in Artemisia annua under copper toxicity. Plant Physiol. Biochem. 2020, 156, 125-134. [CrossRef]

27. Fariduddin, Q.; Yusuf, M.; Hayat, S.; Ahmad, A. Effect of 28-homobrassinolide on antioxidant capacity and photosynthesis in Brassica juncea plants exposed to different levels of copper. Environ. Exp. Bot. 2009, 66, 418-424. [CrossRef]

28. Hu, Z.; Fu, Q.; Zheng, J.; Zhang, A.; Wang, H. Transcriptomic and metabolomic analyses reveal that melatonin promotes melon root development under copper stress by inhibiting jasmonic acid biosynthesis. Horti. Res. 2020, 7, 1-15. [CrossRef]

29. Landa, P.; Dytrych, P.; Prerostova, S.; Petrova, S.; Vankova, R.; Vanek, T. Transcriptomic response of Arabidopsis thaliana exposed to $\mathrm{CuO}$ nanoparticles, bulk material, and ionic copper. Environ. Sci. Technol. 2017, 51, 10814-10824. [CrossRef] [PubMed]

30. Lin, C.Y.; Trinh, N.N.; Fu, S.F.; Hsiung, Y.C.; Chia, L.C.; Lin, C.W.; Huang, H.J. Comparison of early transcriptome responses to copper and cadmium in rice roots. Plant Mol. Biol. 2013, 81, 507-522. [CrossRef]

31. Zhang, Z.; Ke, M.; Qu, Q.; Peijnenburg, W.J.G.M.; Lu, T.; Zhang, Q.; Ye, Y.; Xu, P.; Du, B.; Sun, L.; et al. Impact of copper nanoparticles and ionic copper exposure on wheat (Triticum aestivum L.) root morphology and antioxidant response. Environ. Pollut. 2018, 239, 689-697. [CrossRef]

32. Cao, Y.Y.; Qi, C.D.; Li, S.; Wang, Z.; Wang, X.; Wang, J.; Ren, S.; Li, X.; Zhang, N.; Guo, Y.D. Melatonin alleviates copper toxicity via improving copper sequestration and ROS scavenging in cucumber. Plant Cell Physiol. 2019, 60, 562-574. [CrossRef]

33. Fu, X.Z.; Zhang, X.Y.; Qiu, J.Y.; Zhou, X.; Yuan, M.; He, Y.Z.; Chun, C.P.; Cao, L.; Ling, L.L.; Peng, L.Z. Whole-transcriptome RNA sequencing reveals the global molecular responses and ceRNA regulatory network of mRNAs, lncRNAs, miRNAs and circRNAs in response to copper toxicity in Ziyang Xiangcheng (Citrus junos Sieb. Ex Tanaka). BMC Plant Biol. 2019, 19, 509. [CrossRef]

34. Leng, X.; Jia, H.; Sun, X.; Shangguan, L.; Wu, Q.; Wang, B.; Fang, J. Comparative transcriptome analysis of grapevine in response to copper stress. Sci. Rep. 2015, 5, 17749. [CrossRef] [PubMed]

35. Chen, M.; Fang, X.; Wang, Z.; Shangguan, L.; Liu, T.; Chen, C.; Liu, Z.; Ge, M.; Zhang, C.; Zheng, T.; et al. Multi-omics analyses on the response mechanisms of 'Shine Muscat' grapevine to low degree of excess copper stress (Low-ECS). Environ. Pollut. 2021, 286, 117278. [CrossRef]

36. Sudo, E.; Itouga, M.; Yoshida-Hatanaka, K.; Ono, Y.; Sakakibara, H. Gene expression and sensitivity in response to copper stress in rice leaves. J. Exp. Bot. 2008, 59, 3465-3474. [CrossRef] [PubMed]

37. Guo, P.; Qi, Y.-P.; Huang, W.-L.; Yang, L.-T.; Huang, Z.-R.; Lai, N.-W.; Chen, L.-S. Aluminum-responsive genes revealed by RNA-Seq and related physiological responses in leaves of two Citrus species with contrasting aluminum-tolerance. Ecotoxicol. Environ. Saf. 2018, 158, 213-222. [CrossRef]

38. Guo, P.; Qi, Y.-P.; Yang, L.-T.; Lai, N.-W.; Ye, X.; Yang, Y.; Chen, L.-S. Root adaptive responses to aluminum-treatment revealed by RNA-Seq in two Citrus species with different aluminum-tolerance. Front. Plant Sci. 2017, 8, 330. [CrossRef]

39. Guo, F.; Yu, H.; Xu, Q.; Deng, X. Transcriptomic analysis of differentially expressed genes in an orange-pericarp mutant and wild type in pummelo (Citrus grandis). BMC Plant Biol. 2015, 15, 44. [CrossRef]

40. Burkhead, J.L.; Reynolds, K.A.G.; Abdel-Ghany, S.E.; Cohu, C.M.; Pilon, M. Copper homeostasis. New Phytol. 2009, 182, 799-816. [CrossRef] [PubMed] 
41. Sancenón, V.; Puig, S.; Mira, H.; Thiele, D.J.; Peñarrubia, L. Identification of a copper transporter family in Arabidopsis thaliana. Plant Mol. Biol. 2003, 51, 577-587. [CrossRef]

42. Klaumann, S.; Nickolaus, S.D.; Fürst, S.H.; Starck, S.; Schneider, S.; Neuhaus, E.H.; Trentmann, O. The tonoplast copper transporter COPT5 acts as an exporter and is required for interorgan allocation of copper in Arabidopsis thaliana. New Phytol. 2011, 192, 393-404. [CrossRef]

43. Robinson, N.J.; Procter, C.M.; Connolly, E.L.; Guerinot, M.L. A ferric-chelate reductase for iron uptake from soils. Nature 1999, 397, 694-697. [CrossRef]

44. Welch, R.M.; Norvell, W.A.; Schaefer, S.C.; Shaff, J.E.; Kochian, L.V. Induction of iron(III) and copper(II) reduction in pea roots by Fe and $\mathrm{Cu}$ status: Does the root-cell plasmalemma Fe(III)-chelate reductase perform a general role in regulation of cation uptake. Planta 1993, 190, 555-561. [CrossRef]

45. Jeong, J.; Cohu, C.; Kerkeb, L.; Pilon, M.; Connolly, E.L.; Guerinot, M.L. Chloroplast Fe(III) chelate reductase activity is essential for seedling viability under iron limiting conditions. Proc. Natl. Acad. Sci. USA 2008, 105, 10619-10624. [CrossRef]

46. Zheng, L.; Yamaji, N.; Yokosho, K.; Ma, J.F. YSL16 is a phloem-localized transporter of the copper-nicotianamine complex that is responsible for copper distribution in rice. Plant Cell 2012, 24, 3767-3782. [CrossRef]

47. Blaby-Haas, C.E.; Padilla-Benavides, T.; Stübe, R.; Argüello, J.M.; Merchant, S.S. Evolution of a plant-specific copper chaperone family for chloroplast copper homeostasis. Proc. Natl. Acad. Sci. USA 2014, 111, E5480-E5487. [CrossRef]

48. Del Pozo, T.; Cambiazo, V.; González, M. Gene expression profiling analysis of copper homeostasis in Arabidopsis thaliana. Biochem. Bioph. Res. Commun. 2010, 393, 248-252. [CrossRef]

49. Schiavon, M.; Zhang, L.; Abdel-Ghany, S.E.; Pilon, M.; Malagoli, M.; Pilon-Smits, E.A.H. Variation in copper tolerance in Arabidopsis thaliana accessions Columbia, Landsberg erecta and Wassilewskija. Physiol. Plant. 2007, 129, 342-350. [CrossRef]

50. Huang, H.-Y.; Ren, Q.-Q.; Lai, Y.-H.; Peng, M.-Y.; Zhang, J.; Yang, L.-T.; Huang, Z.-R.; Chen, L.-S. Metabolomics combined with physiology and transcriptomics reveals how Citrus grandis leaves cope with copper-toxicity. Ecotoxicol. Environ. Saf. 2021, 223, 112579. [CrossRef] [PubMed]

51. Hou, X.; Tong, H.; Selby, J.; Dewitt, J.; Peng, X.; He, Z.H. Involvement of a cell wall-associated kinase, WAKL4, in Arabidopsis mineral responses. Plant Physiol. 2005, 139, 1704-1716. [CrossRef]

52. Hayashi, T. Xyloglucans in the primary cell wall. Annu. Rev. Plant Physiol. Plant Mol. Biol. 1989, 40, 139-168. [CrossRef]

53. Zhu, X.F.; Shi, Y.Z.; Lei, G.J.; Fry, S.C.; Zhang, B.C.; Zhou, Y.H.; Braam, J.; Jiang, T.; Xu, X.Y.; Mao, C.Z.; et al. XTH31, encoding an in vitro $\mathrm{XEH} / \mathrm{XET}$-active enzyme, controls $\mathrm{Al}$ sensitivity by modulating in vivo XET action, cell wall xyloglucan content and $\mathrm{Al}$ binding capacity in Arabidopsis. Plant Cell 2012, 24, 4731-4747. [CrossRef] [PubMed]

54. Zhu, X.F.; Wan, J.X.; Sun, Y.; Shi, Y.Z.; Braam, J.; Li, G.X.; Zheng, S.J. Xyloglucan endotransglucosylase-hydrolase17 interacts with xyloglucan endotransglucosylase-hydrolase31 to confer xyloglucan endotransglucosylase action and affect aluminum sensitivity in Arabidopsis. Plant Physiol. 2014, 165, 1566-1574. [CrossRef]

55. Jiang, H.-X.; Yang, L.-T.; Qi, Y.-P.; Lu, Y.B.; Huang, Z.-R.; Chen, L.-S. Root iTRAQ protein profile analysis of two Citrus species differing in aluminum-tolerance in response to long-term aluminum-toxicity. BMC Genomics 2015, 16, 949. [CrossRef] [PubMed]

56. Wang, Z.Q.; Xu, X.Y.; Gong, Q.Q.; Xie, C.; Fan, W.; Yang, J.L.; Lin, Q.S.; Zheng, S.J. Root proteome of rice studied by iTRAQ provides integrated insight into aluminum stress tolerance mechanisms in plants. J. Proteomics 2014, 98, 189-205. [CrossRef]

57. Asada, K. 2000. The water-water cycle as alternative photon and electron sinks. Phil. Trans. R. Soc. Lond. B 2000, 355, 1419-1431. [CrossRef] [PubMed]

58. Cohu, C.M.; Pilon, M. Regulation of superoxide dismutase expression by copper availability. Physiol. Plant. 2007, 129, 747-755. [CrossRef]

59. Abdel-Ghany, S.E.; Burkhead, J.L.; Gogolin, K.A.; Andrés-Colás, N.; Bodecker, J.R.; Puig, S.; Peñarrubia, L.; Pilon, M. AtCCS is a functional homolog of the yeast copper chaperone Ccs1/Lys7. FEBS Let. 2005, 579, 2307-2312. [CrossRef]

60. Huang, C.-H.; Kuo, W.-Y.; Weiss, C.; Jinn, T.L. Copper chaperone-dependent and -independent activation of three copper-zinc superoxide dismutase homologs localized in different cellular compartments in Arabidopsis. Plant Physiol. 2012, 158, 737-746. [CrossRef]

61. Davletova, S.; Rizhsky, L.; Liang, H.; Zhong, S.; Oliver, D.J.; Coutu, J.; Shulaev, V.; Schlauch, K.; Mittleret, R. Cytosolic ascorbate peroxidase 1 is a central component of the reactive oxygen gene network of Arabidopsis. Plant Cell 2005, 17, 268-281. [CrossRef]

62. Lim, J.D.; Hahn, S.J.; Yu, C.Y.; Chung, I.M. Expression of the glutathione S-transferase gene (NT107) in transgenic Dianthus superbus. Plant Cell Tissue Organ Cult. 2015, 80, 277-286. [CrossRef]

63. Zhang, L.; Du, L.; Poovaiah, B.W. Calcium signaling and biotic defense responses in plants. Plant Signal. Behav. 2014, 9, e973818. [CrossRef]

64. Krebs, J.; Agellon, L.B.; Michalak, M. Ca ${ }^{2+}$ homeostasis and endoplasmic reticulum (ER) stress: An integrated view of calcium signaling. Biochem. Bioph. Res. Co. 2015, 460, 114-121. [CrossRef]

65. Teardo, E.; Carraretto, L.; De Bortoli, S.; Costa, A.; Behera, S.; Wagner, R.; Lo Schiavo, F.; Formentin, E.; Szabo, I. Alternative splicing-mediated targeting of the Arabidopsis glutamate receptor 3.5 to mitochondria affects organelle morphology. Plant Physiol. 2015, 167, 216-227. [CrossRef]

66. Teardo, E.; Formentin, E.; Segalla, A.; Giacometti, G.M.; Marin, O.; Zanetti, M.; Lo Schiavo, F.; Zoratti, M.; Szabò, I. Dual localization of plant glutamate receptor AtGLR3.4 to plastids and plasmamembrane. Biochim. Biophys. Acta-Bioenergetics 2011, 1807, 359-367. [CrossRef] 
67. Yan, J.; Guan, L.; Sun, Y.; Zhu, Y.; Liu, L.; Lu, R.; Jiang, M.; Tan, M.; Zhang, A. Calcium and ZmCCaMK are involved in brassinosteroid-induced antioxidant defense in maize leaves. Plant Cell Physiol. 2015, 56, 883-896. [CrossRef]

68. Ma, F.; Lu, R.; Liu, H.; Shi, B.; Zhang, J.; Tan, M.; Zhang, A.; Jiang, M. Nitric oxide-activated calcium/calmodulin-dependent protein kinase regulates the abscisic acid-induced antioxidant defence in maize. J. Exp. Bot. 2012, 63, 4835-4847. [CrossRef] [PubMed]

69. Pearce, G.; Moura, D.S.; Stratmann, J.; Ryan, C.A. RALF, a 5-kDa ubiquitous polypeptide in plants, arrests root growth and development. Proc. Natl. Acad. Sci. USA 2001, 98, 12843-12847. [CrossRef]

70. Zhao, C.; Zayed, O.; Yu, Z.; Jiang, W.; Zhu, P.; Hsu, C.C.; Zhang, L.; Tao, W.A.; Lozano-Durán, R.; Zhu, J.K. Leucine-rich repeat extensin proteins regulate plant salt tolerance in Arabidopsis. Proc. Natl. Acad. Sci. USA 2018, 115, 13123-13128. [CrossRef]

71. Yeh, C.M.; Chine, P.S.; Huang, H.J. Distinct signalling pathways for induction of MAP kinase activities by cadmium and copper in rice roots. J. Exp. Bot. 2007, 58, 659-671. [CrossRef]

72. Burnett, E.C.; Desikan, R.; Moser, R.C.; Neill, S.J. ABA activation of an MBP kinase in Pisum sativum epidermal peels correlates with stomatal responses to ABA. J. Exp. Bot. 2000, 51, 197-205. [CrossRef]

73. Agrawal, G.K.; Agrawal, S.K.; Shibato, J.; Iwahashi, H.; Rakwal, R. Novel rice MAP kinases OsMSRMK3 and OsWJUMK1 involved in encountering diverse environmental stresses and developmental regulation. Biochem. Biophys. Res. Commun. 2003, 300, 775-783. [CrossRef]

74. Schweighofer, A.; Hirt, H.; Meskiene, I. Plant PP2C phosphatases: Emerging functions in stress signaling. Trends Plant Sci. 2004, 9, 236-243. [CrossRef] [PubMed]

75. Singh, A.; Johan, S.K.; Bagri, J.; Pandey, G.K. ABA inducible rice protein phosphatase $2 \mathrm{C}$ confers ABA insensitivity and abiotic stress tolerance in Arabidopsis. PLoS ONE 2015, 10, e0125168. [CrossRef] [PubMed]

76. Liu, X.; Zhu, Y.; Zhai, H.; Cai, H.; Ji, W.; Luo, X.; Li, J.; Bai, X. AtPP2CG1, a protein phosphatase 2C, positively regulates salt tolerance of Arabidopsis in abscisic acid-dependent manner. Biochem. Biophys. Res. Commun. 2012, 422, 710-715. [CrossRef] [PubMed]

77. Ouzounidou, G.; Ilias, I. Hormone-induced protection of sunflower photosynthetic apparatus against copper toxicity. Biol. Plant. 2005, 49, 223-228. [CrossRef]

78. Xiong, L.; Lee, H.; Ishitani, M.; Zhu, J.K. Regulation of osmotic stress-responsive gene expression by the LOS6/ABA1 locus in Arabidopsis. J. Biol. Chem. 2002, 277, 8588-8596. [CrossRef] [PubMed]

79. Wang, Y.; Wang, Y.; Kai, W.; Zhao, B.; Chen, P.; Sun, L.; Ji, K.; Li, Q.; Dai, S.; Sun, Y.; et al. Transcriptional regulation of abscisic acid signal core components during cucumber seed germination and under $\mathrm{Cu}^{2+}, \mathrm{Zn}^{2+}, \mathrm{NaCl}$ and simulated acid rain stresses. Plant Physiol. Biochem. 2014, 76, 67-76. [CrossRef]

80. Zengin, F.K.; Kirbag, S. Effects of copper on chlorophyll, proline, protein and abscisic acid level of sunflower (Helianthus annuus L.) seedlings. J. Environ. Biol. 2007, 28, 561-566.

81. Nguyen, T.Q.; Sesin, V.; Kisiala, A.; Emery, R.J.N. Phytohormonal roles in plant responses to heavy metal stress: Implications for using macrophytes in phytoremediation of aquatic ecosystems. Environ. Toxicol. Chem. 2021, 40, 7-22. [CrossRef] [PubMed]

82. Kuroha, T.; Tokunaga, H.; Kojima, M.; Ueda, N.; Ishida, T.; Nagawa, S.; Fukuda, H.; Sugimoto, K.; Sakakibara, H. Functional analyses of LONELY GUY cytokinin-activating enzymes reveal the importance of the direct activation pathway in Arabidopsis. Plant Cell 2009, 21, 3152-3169. [CrossRef]

83. Thomas, J.C.; Perron, M.; LaRosa, P.C.; Smigocki, A.C. Cytokinin and the regulation of a tobacco metallothionein-like gene during copper stress. Physiol. Plant. 2005, 123, 262-271. [CrossRef]

84. Yang, T.-Y.; Cai, L.-Y.; Qi, Y.-P.; Yang, L.-T.; Lai, N.-W.; Chen, L.-S. Increasing nutrient solution pH alleviated aluminum-induced inhibition of growth and impairment of photosynthetic electron transport chain in Citrus sinensis seedlings. BioMed. Res. Int. 2019, 2019, 9058715. [CrossRef] [PubMed]

85. Guo, P.; Qi, Y.-P.; Cai, Y.-T.; Yang, T.-Y.; Yang, L.-T.; Huang, Z.-R.; Chen, L.-S. Aluminum effects on photosynthesis, reactive oxygen species and methylglyoxal detoxification in two Citrus species differing in aluminum tolerance. Tree Physiol. 2018, 38, 1548-1565. [CrossRef] [PubMed]

86. Lichtenthaler, H.K. Chlorophylls and carotenoids: Pigments of photosynthetic biomembranes. Methods Enzymol. 1987, 148, 350-382.

87. Long, A.; Zhang, J.; Yang, L.-T.; Ye, X.; Lai, N.-W.; Tan, L.-L.; Lin, D.; Chen, L.-S. Effects of low pH on photosynthesis, related physiological parameters and nutrient profile of Citrus. Front. Plant Sci. 2017, 8, 185. [CrossRef]

88. Garg, N.; Kaur, H. Response of antioxidant enzymes, phytochelatins and glutathione production towards Cd and Zn stresses in Cajanus cajan (L.) Millsp. genotypes colonized by arbuscular mycorrhizal fungi. J. Agron. Crop Sci. 2013, 199, 118-133. [CrossRef]

89. Malik, J.A.; Goel, S.; Kaur, N.; Sharma, S.; Singh, I.; Nayyar, H. Selenium antagonises the toxic effects of arsenic on mungbean (Phaseolus aureus Roxb.) plants by restricting its uptake and enhancing the antioxidative and detoxification mechanisms. Environ. Exp. Bot. 2012, 77, 242-248. [CrossRef]

90. Chen, S.; Zhou, Y.; Chen, Y.; Gu, J. fastp: An ultra-fast all-in-one FASTQ preprocessor. Bioinformatics 2018, 34, i884-i890. [CrossRef] [PubMed]

91. Pertea, M.; Pertea, G.M.; Antonescu, C.M.; Chang, T.C.; Mendell, J.T.; Salzberg, S.L. StringTie enables improved reconstruction of a transcriptome from RNA-seq reads. Nature Biotechnol. 2015, 33, 290. [CrossRef] [PubMed] 
92. Liao, Y.; Smyth, G.K.; Shi, W. FeatureCounts: An efficient general purpose program for assigning sequence reads to genomic features. Bioinformatics 2014, 30, 923-930. [CrossRef] [PubMed]

93. Chen, L.; Wu, Q.; He, W.; He, T.; Wu, Q.; Miao, Y. Combined de novo transcriptome and metabolome analysis of common bean response to Fusarium oxysporum f. sp. phaseoli infection. Int. J. Mol. Sci. 2019, 20, 6278. [CrossRef]

94. Mostafa, H.H.A.; Wang, H.; Song, J.; Li, X. Effects of genotypes and explants on garlic callus production and endogenous hormones. Sci. Rep. 2020, 10, 4867. [CrossRef] 